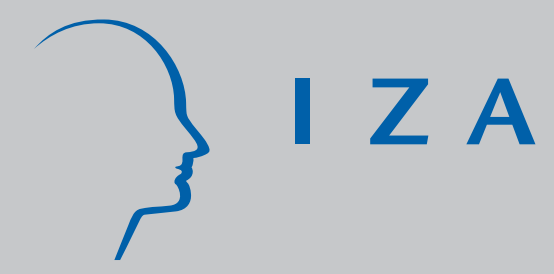

IZA DP No. 3721

Effects of Flat Tax Reforms in Western Europe on Income Distribution and Work Incentives

Alari Paulus

Andreas Peichl

September 2008 


\title{
Effects of Flat Tax Reforms in Western Europe on Income Distribution and Work Incentives
}

\author{
Alari Paulus \\ ISER, University of Essex \\ Andreas Peichl \\ IZA, ISER and University of Cologne \\ Discussion Paper No. 3721 \\ September 2008 \\ IZA \\ P.O. Box 7240 \\ 53072 Bonn \\ Germany \\ Phone: +49-228-3894-0 \\ Fax: +49-228-3894-180 \\ E-mail: iza@iza.org
}

\begin{abstract}
Any opinions expressed here are those of the author(s) and not those of IZA. Research published in this series may include views on policy, but the institute itself takes no institutional policy positions.

The Institute for the Study of Labor (IZA) in Bonn is a local and virtual international research center and a place of communication between science, politics and business. IZA is an independent nonprofit organization supported by Deutsche Post World Net. The center is associated with the University of Bonn and offers a stimulating research environment through its international network, workshops and conferences, data service, project support, research visits and doctoral program. IZA engages in (i) original and internationally competitive research in all fields of labor economics, (ii) development of policy concepts, and (iii) dissemination of research results and concepts to the interested public.
\end{abstract}

IZA Discussion Papers often represent preliminary work and are circulated to encourage discussion. Citation of such a paper should account for its provisional character. A revised version may be available directly from the author. 


\title{
ABSTRACT
}

\section{Effects of Flat Tax Reforms in Western Europe on Income Distribution and Work Incentives}

\begin{abstract}
The flat income tax has become increasingly popular recently, yet its implementation is limited to Eastern Europe. We analyse the distributional and efficiency effects of flat tax scenarios for Western European countries. Our simulations show that flat tax rates required to attain revenue neutrality with existing basic allowances improve labour supply incentives. However, they result in higher inequality and polarisation. Flat rates necessary to keep the inequality levels unchanged allow for some scope for flat taxes to increase both equity and efficiency. Our analysis suggests that Mediterranean countries are more likely to benefit from flat taxes.
\end{abstract}

JEL Classification: $\quad$ C81, D31, H24

Keywords: flat tax reform, income distribution, work incentives, microsimulation

Corresponding author:

Andreas Peichl

IZA

P.O. Box 7240

53072 Bonn

Germany

E-mail: peichl@iza.org

\footnotetext{
* This paper uses EUROMOD version C13. EUROMOD is continually being improved and updated and the results presented here represent the best available at the time of writing. Any remaining errors, results produced, interpretations or views presented are the authors' responsibility. EUROMOD relies on micro-data from twelve different sources for fifteen countries.

This paper uses data from the European Community Household Panel (ECHP) User Data Base made available by Eurostat; the Austrian version of the EU-SILC made available by Statistik Austria; the Panel Survey on Belgian Households (PSBH) made available by the University of Liège and the University of Antwerp; the Income Distribution Survey made available by Statistics Finland; the public use version of the German Socio Economic Panel Study (GSOEP) made available by the German Institute for Economic Research (DIW), Berlin; the Greek Household Budget Survey by the National Statistical Service of Greece; the Socio-Economic Panel for Luxembourg (PSELL-2) made available by CEPS/INSTEAD; the Socio-Economic Panel Survey (SEP) made available by Statistics Netherlands through the mediation of the Netherlands Organisation for Scientific Research - Scientific Statistical Agency, and the Family Expenditure Survey (FES), made available by the UK Office for National Statistics (ONS) through the Data Archive. Material from the FES is Crown Copyright and is used by permission. Neither the ONS nor the Data Archive bears any responsibility for the analysis or interpretation of the data reported here. An equivalent disclaimer applies for all other data sources and their respective providers.

This paper is based on work carried out during a visit to the European Centre for Analysis in the Social Sciences (ECASS) at the Institute for Social and Economic Research (ISER), University of Essex, supported by the Access to Research Infrastructures action under the EU Improving Human Potential Programme.

Andreas Peichl is grateful for financial support by the Fritz Thyssen foundation. We would like to thank Clemens Fuest and Stephen Pudney and participants of ECINEQ, I-CUE and IMA conferences and seminars in Cologne, Essex and Mannheim for helpful comments and suggestions. We are indebted to all past and current members of the EUROMOD consortium for the construction and development of EUROMOD. However, any errors and the views expressed in this paper are the authors' responsibility. In particular, the paper does not represent the views of the institutions to which the authors are affiliated.
} 


\section{Introduction}

Flat income tax, referring broadly to a tax with a single marginal rate, is becoming increasingly popular. Before the 1990s it was only applied in a few countries, most prominently Hong Kong and the Channel Islands. Since 1994 however, after its introduction in Estonia, a number of countries have followed suit. In 2008 there were altogether 26 countries worldwide with flat tax systems, of which about half are in Eastern Europe, and such proposals being discussed in several other countries including some in Western Europe. ${ }^{1}$ However, among the latter only Iceland recently adopted a flat tax.

There are three main benefits usually associated with flat tax systems. First, flat taxes may enhance labour supply incentives. Although there is a trend of lowering marginal statutory tax rates (and reducing the number of tax brackets), top rates can still be rather high in existing systems, e.g. around 40-60\% in EU15 (see Eurostat (2007)). While the gains from lower and flat tax rates are explicit for the top income range, they are not so obvious for low incomes. The results here depend on the chosen flat tax parameters and the underlying income distribution. Second, a flat tax can increase tax compliance and reduce tax evasion. This argument is perhaps weaker in developed countries, but it is often central for this kind of reform in developing and transition countries. Third, as a flat tax is often a part of more fundamental tax reform, it can simplify income taxation significantly. The current systems in Europe have typically evolved to quite complex entities, often violating the principle that taxes ought to be clear and simple. A simpler system is not only easier to grasp from the point of view of a single taxpayer, but is also more transparent at the aggregated level. Simplification can also decrease the costs of administration and compliance.

However, flat taxes can have a serious drawback in terms of their impact on the distribution of tax burdens which could be the main reason limiting its spread in developed countries with a well established middle class. Previous flat tax reforms and typical proposals lower marginal tax rates at the high income levels but increase the tax burden for middle-income ranges, resulting in a widening of the distribution of after-tax incomes.

Only two actual reforms have been examined in the literature: the 2001 Russian reform by Ivanova et al. (2005) and the 2004 reform in the Slovak Republic by, among others, Brook and Leibfritz (2005). In the Russian case, the reform was followed by significant real growth in personal income tax revenue, but there was no strong evidence that this was caused by the reform itself or by improved law enforcement, nor could any positive labour supply responses be identified. ${ }^{2}$ The Slovakian reform was expected to be revenue neutral, to increase the level

\footnotetext{
${ }^{1}$ Cf. Keen et al. (2007), Nicodeme (2007) and Mitchell (2007). See also Figure 11 in Appendix A.

${ }^{2}$ See also Gaddy and Gale (2005) and Gorodnichenko et al. (2007). Furthermore, the situation in Russia is different in comparison to Western European countries insofar as the latter have a long tradition of taxation and
} 
and efficiency of capital formation and enhance the incentives of unemployed workers to seek work. However, no evidence apart from revenue-neutrality has been reported yet. While it is true that most real world reforms have been very recent, research on their effects is probably also limited due to the lack in those countries of high-quality (micro-)data for the pre-reform period.

In the discussion of the flat tax "a notable and troubling feature [... is that it has been marked more by rhetoric and assertion than by analysis and evidence". ${ }^{3}$ Given that flat taxes have not yet been implemented in Western countries, the effects of flat tax reforms in these countries can only be studied on the basis of simulation models. There have been several previous studies, focussing on a single country and hypothetical reforms in most cases. In a study for the Netherlands, Caminada and Goudswaard (2001) derive the result that a flat tax would yield redistribution at the expense of the lowest income deciles, but the magnitude of these effects is quite small. Several studies, like Aaberge et al. (2000) for Italy, Norway and Sweden, Kuismanen (2000) for Finland, Adam and Browne (2006) for the UK, GonzálezTorrabadella and Pijoan-Mas (2006) for Spain ${ }^{4}$, and Decoster and Orsini (2007) for Belgium, find that, in addition to redistribution in favour of high income households, the hypothetical introduction of a flat tax would increase labour supply (incentives). Benedek and Lelkes (2007) simulate a flat tax reform for Hungary. They do not consider work incentives but also find that the reform would lead to a sharp increase in after tax income inequality. Fuest et al. (2008) show for Germany that a flat tax with a high basic allowance and a single rate has less harmful distributional effects than a flat tax with a low rate. The latter scenario, however, is the only alternative that leads to positive, albeit small, labour supply and welfare effects. Jacobs et al. (2007) analyse two revenue neutral flat tax scenarios on the basis of a computable general equilibrium model calibrated for the Netherlands. The low flat rate scenario increases inequality because taxes on low incomes increase whereas high income earners benefit. There are positive effects on employment, which increases by 1.4 per cent. In the second scenario, the general tax credit and the marginal rate are higher. Now, also low incomes benefit due to the higher tax credit, while very high incomes gain less than in the low tax scenario. Middle income households, however, face an increasing tax burden. Aggregate labour supply and employment fall.

The aim of this paper is to undertake a systematic approach for choosing flat tax parameters

a rather large tax administration to ensure tax compliance. Therefore, we assume effects of a flat tax reform on compliance to be less important than in transition countries of Eastern Europe.

${ }^{3}$ Keen et al. (2007), p. 3.

${ }^{4}$ The findings in González-Torrabadella and Pijoan-Mas (2006) differ from the other country studies in the magnitude of the simulated efficiency gains. While most studies find rather small gains, their model predicts an increase in output by more than $5 \%$. They argue that this is driven mostly by an increase in capital formation, not in employment. 
for a comparative analysis of different flat tax designs for selected Western European countries. Davies and Hoy (2002) show that in the case of revenue neutral flat tax reforms there are two sets of critical parameter values: a lower bound of the flat tax rate below which inequality is always higher compared to a given graduated rate tax, and an upper bound above which inequality is always lower. We rely on these theoretical insights to systematically construct hypothetical flat tax reforms and analyse the distributional and incentive effects of their implementation in European countries.

We use EUROMOD, a tax-benefit microsimulation model for the EU15, to compare the results across countries in a common framework. Among others, we study the effects on polarisation, which can be used as an indicator of the strength of the middle class. We ask whether different combinations of tax rates and allowances always have an adverse effect on the middle class and if there are indeed positive incentive effects. We concentrate on the short-term static effects assuming that these decide the political feasibility of a tax reform although there are possibly important long-term effects as well. ${ }^{5}$

Our analysis yields the following results. The flat tax rates required to attain revenue neutrality with existing basic allowances (lower boundary) improve labour supply incentives. However, they benefit mainly those with high incomes at the expense of low and middle income households, resulting in more inequality, poverty and polarisation of the income distributions. On the other hand, revenue neutral flat rates necessary to keep the inequality levels unchanged are rather high and lead to ambiguous incentive effects. In general, a revenue neutral flat tax reform cannot overcome the fundamental equity-efficiency trade-off, but in some cases an increase in equality and work incentives is possible. We show that the different underlying income distributions and compositions of welfare state regimes play a key role for the results in terms of both equity and efficiency. Overall, this could contribute to explaining why flat taxes have not been politically successful in Western Europe so far. This also suggests that Mediterranean countries with a rather small middle-class due to high polarisation are more likely to benefit from such a reform.

The rest of the paper is organised as follows: section 2 provides a discussion on the flat tax design. Section 3 contains a short description of the model, datasets and our reform scenarios. Section 4 illustrates the distributional effects in terms of inequality, poverty and richness, polarisation, winners and losers as well as the incentive effects in terms of effective marginal and average tax rates. Section 5 concludes.

\footnotetext{
${ }^{5}$ People tend to judge future gains and losses asymmetrically (see e.g. the "prospect theory" by Kahneman and Tversky (1979)). Starting from a reference point (status quo) and given the same variation in absolute values, there is a bigger impact of losses than of gains (loss aversion). Furthermore, people prefer the status quo over uncertain outcomes in the future ("status-quo-bias", see Kahneman et al. (1991)). Therefore, short-term losses in comparison to the status quo can have a much stronger impact than (possible) future gains. Hence, the short term effects presented here could be decisive.
} 


\section{Flat tax design}

Flat tax implies that some sort of proportionality is embedded in the income tax system, i.e. income is taxed at the same (flat) rate along the whole range of income. Its design, however, can be very different. There are two dimensions to be distinguished: tax schedule and tax base. In general, a tax schedule can apply the same rate on all sources of income (i.e. comprehensive tax) or different rates on different types of incomes (i.e. schedular tax). Most countries with a flat tax system apply different rates to personal and corporate income, although a common rate has become more popular among the countries recently implementing these systems. Usually, the tax rate does not vary for components of personal income, i.e. capital and labour income is taxed at the same marginal rate independent of the level of income. There is also a number of countries which tax only capital income at a flat rate and levy a progressive rate schedule on labour income. However, these are usually not considered as flat tax systems but dual or semidual income tax systems. ${ }^{6}$ For the tax base one can differentiate between concepts allowing or not allowing for any allowances or deductions. Certainly, only the flat tax without any tax reliefs is a "pure" flat tax as in this case tax payments are indeed proportional to incomes. A flat income tax as such has only been applied in Georgia and recently in Bulgaria. In all other cases, the tax incidence on incomes is progressive, i.e. a single marginal flat tax rate $t$ is combined with a general personal flat tax allowance $a$. This is also what we consider in this paper:

$$
T=t * \max (\text { taxbase }-a, 0)
$$

An important aspect which has been rarely addressed in previous studies is the setting of tax system parameters for the ex ante analysis of hypothetical tax reforms. In terms of flat tax reforms this translates into the question of how to set the flat tax rate and the basic allowance. In our case we are interested in the relationship between flat tax parameters and distributional effects. ${ }^{7}$ Davies and Hoy (2002) show theoretically that the inequality of after-tax distribution of income is monotonically declining in the flat tax rate and the associated level of basic allowance generating the same tax yield. ${ }^{8}$ Furthermore, for revenue neutral tax reforms replacing a graduated rate tax (GRT) with a flat rate tax (FRT), they prove the existence of critical flat tax rates such that compared to the (existing) graduated rate tax after-tax income

\footnotetext{
${ }^{6}$ See OECD (2006) for more about dual income tax systems. These countries include e.g. the Scandinavian countries.

${ }^{7}$ The setting of the key flat tax design features (marginal rate, basic allowance, tax base) crucially depends on the objective of the reform (like simplifying the system, improving compliance, broadening the tax base, increasing or decreasing the tax burden for selected groups, higher, lower or constant revenue) and if other reforms (like shifting tax burden between direct and indirect taxes or taxes and social insurance) are planned to accompany the flat tax introduction.

${ }^{8}$ As a flat tax schedule has only two parameters - marginal rate and basic allowance - it is only possible to choose one freely when accounting for revenue neutrality.
} 
inequality is:

A) the same for a given inequality index at a certain flat tax rate, $t=t_{F}^{*} \in\left(t_{F}^{l}, t_{F}^{u}\right)$,

B) always higher (according to any inequality index) for any flat tax rate equal to or below a lower bound, $t \leq t_{F}^{l}$,

C) always lower (according to any inequality index) for any flat tax rate equal to or above an upper bound, $t \geq t_{F}^{u}$.

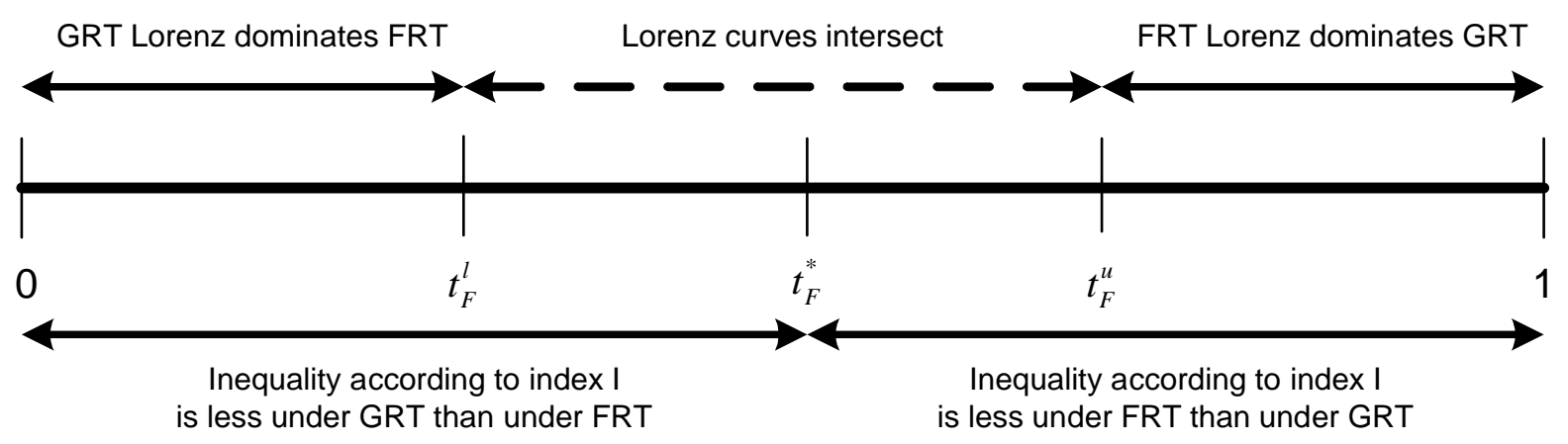

Figure 1: Comparison of critical flat tax rates

Source: Davies and Hoy (2002), p. 40.

Figure 1 illustrates these regularities. In other words: when moving from a graduated income tax to a flat tax system that yields the same revenue, three critical flat tax rate values with respect to after-tax income inequality exist. The first depends on the chosen inequality index, the other two do not, i.e. they stem from the concept of Lorenz dominance. First, for a given inequality index $I$, a flat rate value $t_{F}^{*}$ can be found such that inequality remains unchanged. Further on, inequality in terms of this index is always higher (lower) below (above) this critical value after the flat tax introduction. Second, there exist a lower bound $t_{F}^{l}$ such that for all marginal rates below this critical value inequality in terms of any inequality measure is always higher than compared to the existing system (i.e. the existing graduated rate tax Lorenz dominates the flat tax). Third, inequality is always lower above an upper bound $t_{F}^{u}$ according to any inequality index (i.e. the flat tax Lorenz dominates the existing graduated rate tax). These regularities apply to any inequality measure satisfying the Pigou-Dalton principle of transfers and under the assumption that behaviour is not affected by tax system changes.

The lower bound corresponds to a flat tax rate if the personal allowance is fixed, i.e. is at the same level as for the pre-reform graduated rate tax. The upper bound is such that a person with the highest income pays the same tax under each scheme. Additionally, the flat rate at the lower bound is supposed to exceed the lowest marginal tax rate under the graduated rate 
and the flat rate at the upper bound remains below the highest marginal tax rate under the graduated rate. The critical value between those boundaries cannot be determined a priori as it depends on a chosen inequality index. ${ }^{9}$

We rely on these theoretical insights to systematically construct hypothetical flat tax reforms. However, these theoretical regularities are only approximations for empirical estimations because existing tax systems are further complicated by the presence of other tax deductions and allowances. Some systems do not even have a (well-defined) basic allowance to start with. More so, the definition of revenue neutrality is not straightforward. If revenue neutrality is only limited to income taxes then it might not preserve the mean of the disposable income distribution, as there are often instruments whose eligibility or amount depend on net income after taxes (e.g. means-tested non-taxable benefits) and, therefore, might change their value when tax systems are modified. If the overall net balance from taxes and benefits is retained then income tax revenues rarely remain constant. Further on, the premise of ex-ante revenue neutrality (i.e. without behavioural responses) is a rather strong assumption but it is necessary to apply the Davies and Hoy (2002) approach. ${ }^{10}$

In practice, most countries have introduced a flat tax rate at or close to the level of previous lowest marginal rate. Exceptions are Latvia and Lithuania who have chosen rates close to the previous highest marginal rate (Nicodeme (2007)). The Slovak Republic and Estonia initially opted for a rate in the middle range, although the latter is now gradually moving towards the former lowest marginal rate as well. The pattern of setting basic allowances however is less clear. In most countries an allowance in fixed amount was retained or introduced. Exceptions include Russia with gradual withdrawal and Ukraine with sudden withdrawal above certain income levels which makes the effective marginal tax rate high at some stages. However, the amount of allowance varies significantly, most countries having it increased during the reforms (Keen et al. (2007)). For example, Georgia has no allowance at all, the allowance in Russia was about $12 \%$ of the average gross wage in the year before and after the reform (i.e. 2000-01), in Estonia it was 40-74\% of the minimum wage and 11-21\% of the average gross wage in 1994-2006, and in the Slovak Republic it exceeded the minimum wage and was about $60 \%$ of the average wage in 2004, more than doubled with the reform (see Brook and Leibfritz (2005)).

\footnotetext{
${ }^{9}$ Chiu (2007) demonstrates further that for an index exhibiting downside inequality aversion this value is determined by the strength of the index's downside inequality aversion against its inequality aversion. In the case of Generalized Entropy Indices $E(\alpha)$, since a higher $\alpha$ indicates a weaker downside inequality aversion against inequality aversion, it also implies a higher critical flat tax rate between the boundaries.

${ }^{10}$ If the scenarios were chosen to be revenue neutral ex-post, i.e. after labour supply reactions, the marginal tax rates could be lower (higher) in case of increasing (decreasing) labour supply but the underlying research question would be different. Our aim is to analyse scenarios that are equal ex-ante and to reveal the ex-post differences by analysing the economic effects of the scenarios in terms of equity and efficiency.
} 


\section{$3 \quad$ Flat tax simulations}

\subsection{EUROMOD: model and database}

We use the microsimulation technique to simulate taxes, benefits and disposable incomes under different scenarios for a representative micro-data sample of households. Simulations are done with EUROMOD, a static tax-benefit model covering the EU15 countries. EUROMOD was built by a consortium of research institutions from each EU15 country with a good knowledge and expertise in their national tax-benefit system. The model has been validated against aggregated administrative statistics and national tax-benefit models (where available), and found to perform satisfactorily. ${ }^{11}$

Our analysis is based on the 2003 tax-benefit systems, which is the most recent wave currently available in EUROMOD but limited to 10 countries, excluding Denmark, France, Ireland, Italy and Sweden (see also Figure 11 in Appendix A). The main stages of the simulations are the following. First, a micro-data sample and tax-benefit rules are read into the model. Then for each tax and benefit instrument, the model constructs corresponding units of assessment, ascertains which are eligible for that instrument and determines the amount of benefit or tax liability. The result is then either assigned to an individual or allocated to members of the tax unit. Finally, after all taxes and benefits in question are simulated, disposable income is calculated.

EUROMOD is characterised by greater flexibility than typical national models, to accommodate a range of different tax-benefit systems. For instance, the model can easily handle different units of assessment, income definitions for tax bases and benefit means-tests, the order and structure of instruments. Overall, a common framework allows the comparison of countries in a consistent way.

EUROMOD covers only monetary incomes, excluding capital gains and irregular incomes. It can simulate most direct taxes and benefits except those based on previous contributions as this information is usually not available from the cross-sectional survey data used by EUROMOD as input datasets. The model assumes full benefit take-up and tax compliance. Although the latter is an important aspect of flat tax reforms, we do not consider changes in compliance here and limit our analysis to first-order static effects only.

Table 2 in Appendix A gives an overview of the input datasets for EUROMOD. Their sample size varies across countries from less than 2,500 to more than 11,000 households. All monetary variables are updated to year 2003 using country-specific uprating factors, as the survey period

\footnotetext{
${ }^{11}$ For further information on EUROMOD, see Sutherland (2001) and Sutherland (2007). Additional information including country reports regarding the detailled modelling of each country's tax benefit system is available at http://www.iser.essex.ac.uk/msu/emod/ .
} 
for incomes varies from 1999 to 2003. Where net incomes were recorded in the original data, gross incomes have been also imputed. For further information on EUROMOD, see Sutherland (2001) and Sutherland (2007).

\subsection{Current income tax systems}

The existing income tax systems in the 10 countries under consideration are quite varied. As of 2003, all have graduated rate schedules with a number of brackets ranging from 3 (UK) to 16 (Luxembourg) and the highest marginal tax rate from 38\% (Luxembourg) to about 55\% (Finland, state and local rate combined). All schedules are piecewise linear except that of Germany which has a unique continuous function for tax rates at some income levels. Seven countries have a general basic allowance, often integrated into the tax schedule; the Netherlands and Portugal apply general (wastable) tax credits and Austria uses both elements. About half of the countries tax capital income (and property income) together with other income and the rest tax it separately applying a flat rate (of 15-30\%), in Belgium this is optional.

The countries also differ in the unit of assessment. Again, half of them allow only individual taxation, four countries apply either optional or compulsory joint taxation and Belgium provides limited income sharing for married couples. Nevertheless, even systems based on individual taxation often have elements assessed at family level or couple level (e.g. family or child allowances) or allow the sharing of non-labour income or household expenditures (e.g. property income, mortgage payments). Table 3 in Appendix A summarises these characteristics.

Overall, although there are few countries with relatively simple income tax systems (e.g. UK), most of them can be characterised as complex systems with the combination of many different elements and varying tax units. Additional examples of complexities include progression adjustments in Austria and Germany, income taxation both at the state and the local level in Finland, and an integrated schedule of social insurance contributions and income tax in the Netherlands.

\subsection{Reform scenarios}

In our flat tax reform simulations we replace all existing personal income tax deductions, allowances and credits with a single personal allowance (which is equivalent to a wastable, i.e. non-refundable, tax credit), and each graduated rate schedule with a flat rate. We only keep refundable tax credits as these are equivalent to benefits. ${ }^{12}$ In countries where capital income was taxed at a separate rate, we abolish this separate rate and include capital income in the

\footnotetext{
${ }^{12}$ Examples include the lone parent tax credit in Austria, the tax credit for families with school children in Greece, working mother tax credit in Spain and working tax credit and child credit in the UK.
} 
flat tax base. Therefore, our reform scenarios have a good potential to simplify the systems (due to fewer specific deductions) and make them more transparent. ${ }^{13}$

We do not attempt to harmonise tax bases across countries, we limit ourselves to income taxes and do not modify existing social insurance contribution schemes (SIC) ${ }^{14}$ or benefits. One could also carry out an exercise of simply flattening tax rate schedules without adjusting the tax base, but this would result in higher flat tax rates due to retained exceptions, therefore, limiting gains in terms of incentives.

We simulate the following three flat income tax scenarios for each country:

- a revenue neutral flat rate with a basic allowance in the existing (or equivalent) amount $(\mathrm{S} 1)$,

- a 10 percentage points higher flat rate compared to the first scenario and an increased tax allowance to preserve revenue neutrality (S2),

- a 20 percentage points higher flat rate compared to the first scenario and an increased tax allowance to preserve revenue neutrality (S3).

All scenarios are revenue neutral with the total income tax revenue within $\pm 0.1 \%$ limits of its baseline value. In terms of Davies and Hoy (2002) approach, our first scenario should approximately correspond to the lower bound. Because of additional complexities discussed in section 2 exact critical flat tax rates cannot be identified in a straightforward manner. The 10 and 20 percentage point higher tax rate under the second and the third scenario are chosen to explore the effect on inequality potentially around the upper bound. ${ }^{15}$

Figure 2 plots the flat tax rate under each scenario and the lowest and highest (positive) tax rate of the existing tax rate schedules. Because of revenue neutrality the tax allowance is not independent of the tax rate. There is notable variation in the flat tax rate under the first scenario (11.6-33.9\%). This variation results from the combination of the underlying pretax income distribution and average effective tax burden under the existing system. This also affects the other two scenarios. However, it turns out that for most countries the range of flat tax rates under three scenarios roughly matches the range of existing tax rates. A notable exception is the Netherlands with a very wide range of graduated tax rates. ${ }^{16}$

\footnotetext{
${ }^{13}$ Further on, abolishing specific deductions and allowances (that may have different values for different persons or income levels) and replacing them with one general allowance leads to a (slightly) broader tax base.

${ }^{14}$ The use of social insurance contributions differs considerably across European countries. Therefore, a SIC reform would raise further conceptual questions, e.g. if mandatory contributions should be interpreted as taxes or insurance premium.

${ }^{15}$ One could also construct scenarios with varying increases in the tax rates across countries generating the same increase in inequality. This would lead to a slightly different research question with the focus more on the level of the tax rates than on inequality measures. We have chosen the approach of constant increases for a better comparability of scenarios across countries in terms of distributional effects.

${ }^{16}$ The integrated schedule of social insurance contributions and income tax in the Netherlands results in
} 


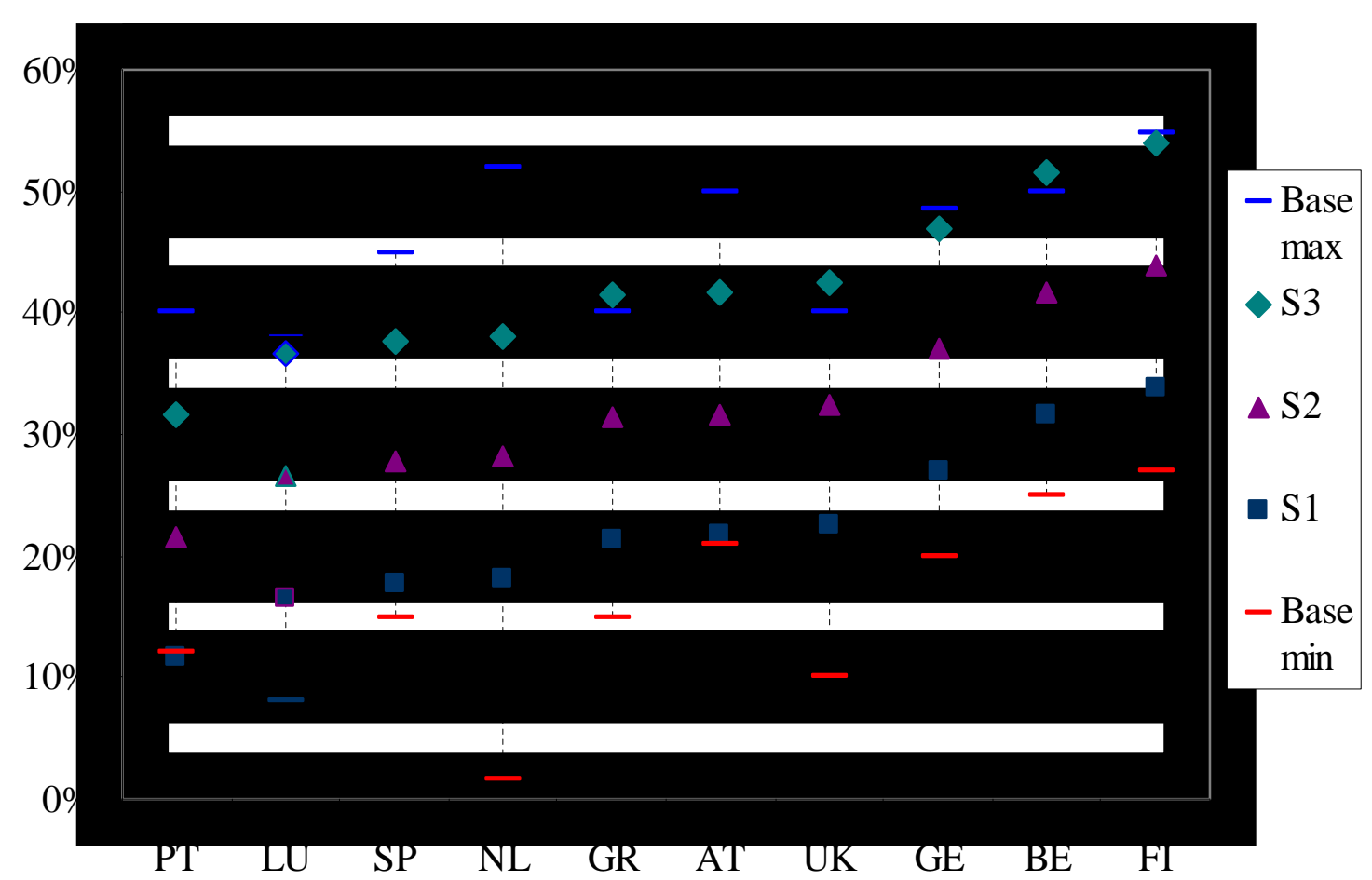

Figure 2: Simulated flat tax rates and existing lowest and highest marginal rate

As expected, flat tax rates under the first scenario are above the lowest rates in the existing schedules with only Portugal being slightly lower, which is possibly due to the elimination of additional tax allowances. Flat tax rates under the third scenario are around the previous highest marginal rates for six countries and below that for the rest.

\section{Simulation results}

In this section we present the results of our analysis. First, we analyse the distributional effects of the different scenarios. This is followed by the presentation of the progressivity effects and then summarised by the share of winners and losers. Finally, we demonstrate how effective average and marginal tax rates change according to the simulated reform scenarios. ${ }^{17}$

rather low income tax rates for the brackets where full contributions to the "People's Pensions Insurance" have to be paid and rather high rates above the SIC threshold.

${ }^{17}$ When interpreting the results, one has to be aware of the fact that revenue neutrality in terms of (overall) tax payments does not necessarily imply a constant mean disposable income. This mainly depends on meantested benefits which are calculated on the basis of after-tax net income. 


\subsection{Inequality, poverty, richness and polarisation}

We compute a number of distributional measures to cover several aspects of distribution: inequality, polarisation, poverty and richness. These are based on equivalised household disposable incomes. ${ }^{18}$ To analyse income inequality we use the Gini coefficient and the Generalised Entropy indices with sensitivity parameters $\alpha=0$ (Mean Log Deviation), $\alpha=1$ (Theil index) and $\alpha=2$. Figure 3 presents the Gini coefficient for each scenario, other measures are presented in Table 7 (Appendix B).

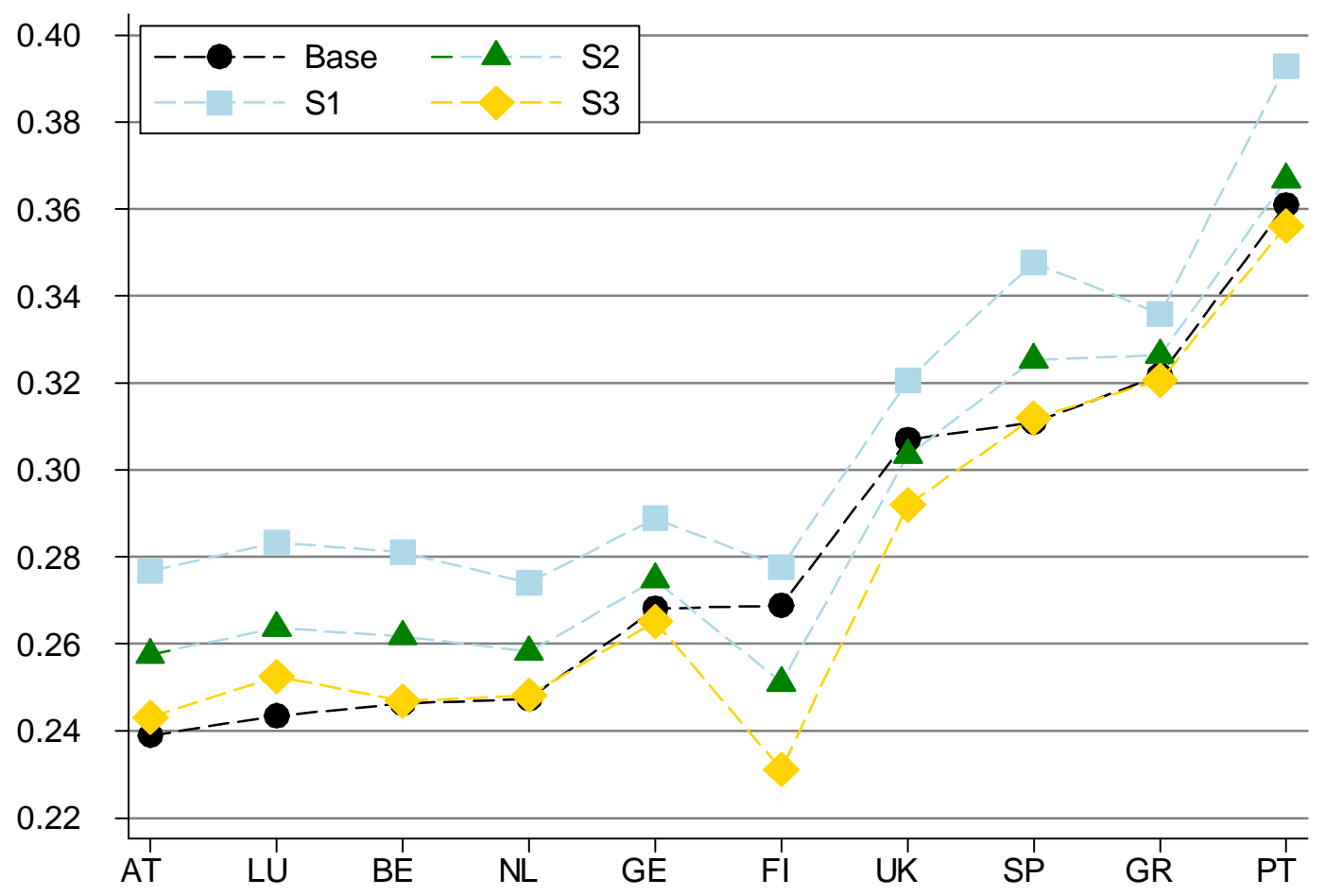

Figure 3: Income inequality by the Gini coefficient

First, there are already distinct differences between the countries in terms of disposable income inequality in the baseline scenario which can be to some extent explained by the gross income distribution. Two groups are afferent: inequality is rather high in Southern European countries (Greece, Portugal and Spain) and the UK, and is rather low in Continental Europe (Austria, Germany and the Benelux countries) and Finland. This classification of countries corresponds to the typology by Esping-Andersen (1990) who differentiates between three types of welfare states: conservative (Continental Europe), social-democratic (Nordic Europe) and

\footnotetext{
${ }^{18}$ We use the modified OECD equivalence scale which weights the household head with a factor of 1 , household members aged 14 and older with 0.5 , and under 14 with 0.3 . The household net income is divided by the sum of the individual weights of each member (=equivalence factor) to compute the equivalent household income.
} 
liberal (Anglo-Saxon). Ferrera (1996) further adds a fourth category (Mediterranean) to this typology.

Introducing a revenue neutral flat tax increases inequality unambiguously only under the first scenario (S1), i.e. the lower bound. In the second scenario (S2) inequality decreases relative to the baseline for Finland and the UK (depending on the inequality measure for the latter) and in the third scenario (S3) also for Belgium, Germany, Greece and Portugal. ${ }^{19}$ These differences between countries can be explained to some extent by different tax systems and the resulting distribution of tax payments. The latter is rather narrow in Belgium, Finland and the UK, where inequality decreases, with a spread of the effective average tax rate in the baseline between the lowest and highest decile of less than 20 percentage points whereas this spread in most other countries is around or well above 30 percentage points. ${ }^{20}$

The scenarios can be ranked according to the level of inequality as follows: $I(S 1)>I(S 2)>$ $I(S 3) .{ }^{21}$ The increases in inequality, however, are similar in absolute terms for most countries with FI and UK being slightly lower. The fact that inequality levels under the third scenario are below or close to those in the baseline scenario show that they correspond approximately to the critical value or upper boundary respectively. ${ }^{22}$

To analyse the effects of flat taxes on poverty we compute the headcount index and the measures of Foster et al. (1984) based on the poverty line taken from the baseline scenario. ${ }^{23}$ We compute the poverty lines as $60 \%$ of median equivalent income for each country. The results for the headcount ratio (FGT0) are plotted in Figure 4 and the full results are presented in Table 5 (Appendix B). Measuring richness is a much less considered field in the literature than poverty. We compute the headcount index and the measures of Peichl et al. (2006) which are analogously defined to the FGT indices of poverty. The richness line is computed as $200 \%$ of median equivalent income. The results for the headcount ratio are presented in Figure 5 and the full results in Table 6 (Appendix B). ${ }^{24}$

Again, there are distinct differences between countries in the baseline levels of poverty and

\footnotetext{
${ }^{19}$ These derived results are in line with comparable scenarios from single country studies. Fuest et al. (2008), for example, find a similar increase in inequality for scenario S1 and one close to S2 for Germany.

${ }^{20}$ This spread, however, is largest for Greece although a similar development can be observed as for lowspread countries. But when taking a closer look at the distribution of tax payments it can be seen that it is right-skewed and the spread between deciles one and nine is below 20 pp. See subsection 4.2 and Table 9 (Appendix C) for further information.

${ }^{21}$ This ordering is stable when using any inequality index presented in Table 7 (Appendix B).

${ }^{22}$ Inequality under S3 is lower for those countries where flat tax rate under S3 is close or exceeds previous highest rate (GR, UK, GE, BE, FI), except LU, and additionally for PT.

${ }^{23}$ We fix the poverty and richness lines at the baseline level to account for (possible) changes in median income. Otherwise, if we would allow for changing poverty (richness) lines an increasing measure of poverty (or a decreasing index of richness) would not necessarily indicate a worse situation for people with low (high) incomes as a result of the changing poverty (richness) line.

${ }^{24}$ One should note, though, that measuring richness depends on the quality of micro data as the upper tail of the income distribution in surveys is especially prone to non-response and measurement error bias.
} 


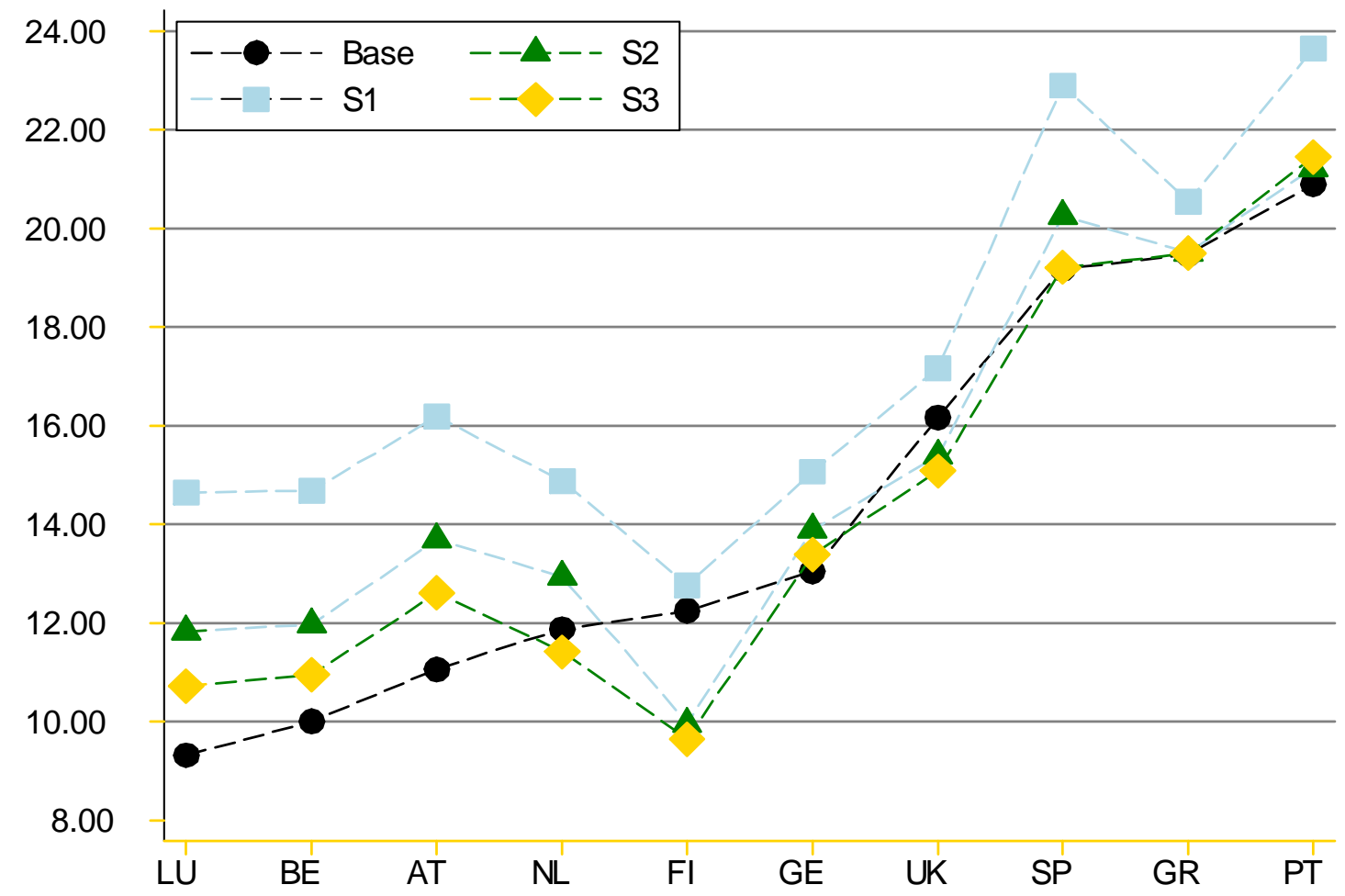

Figure 4: Poverty rates by the headcount ratio (with constant poverty line), \%

richness. The same two groups of countries can be distinguished: like inequality, poverty and richness are rather high in Southern European countries (Greece, Portugal and Spain) and the UK, and low in Continental Europe (Austria, Belgium Germany, Luxembourg) and Finland.

Poverty increases in terms of all measures in all scenarios compared to the baseline, except for the Netherlands in S3 and Finland and the UK in S2 and S3. When analysing poverty, one has to take into account the fact that the lowest deciles of the income distribution seldom pay income taxes. There is, therefore, limited scope for a reduction in income poverty through reduced marginal tax rates. The pattern of changes in richness measures matches closely the inequality measures, i.e. increasing richness in the first scenario for all countries and measures, decreasing richness for Finland and the UK in the second scenario relative to the baseline and additionally for Belgium and Germany in the third scenario. These effects differ slightly when using more sophisticated richness measures $\left(R_{\alpha}\right)$ that also account for changes in the dimension of richness and not only the number of people above a richness line. Richness is then also decreasing for Portugal and Greece in S3.

To assess the importance of the middle class we calculate the polarisation index of Schmidt 


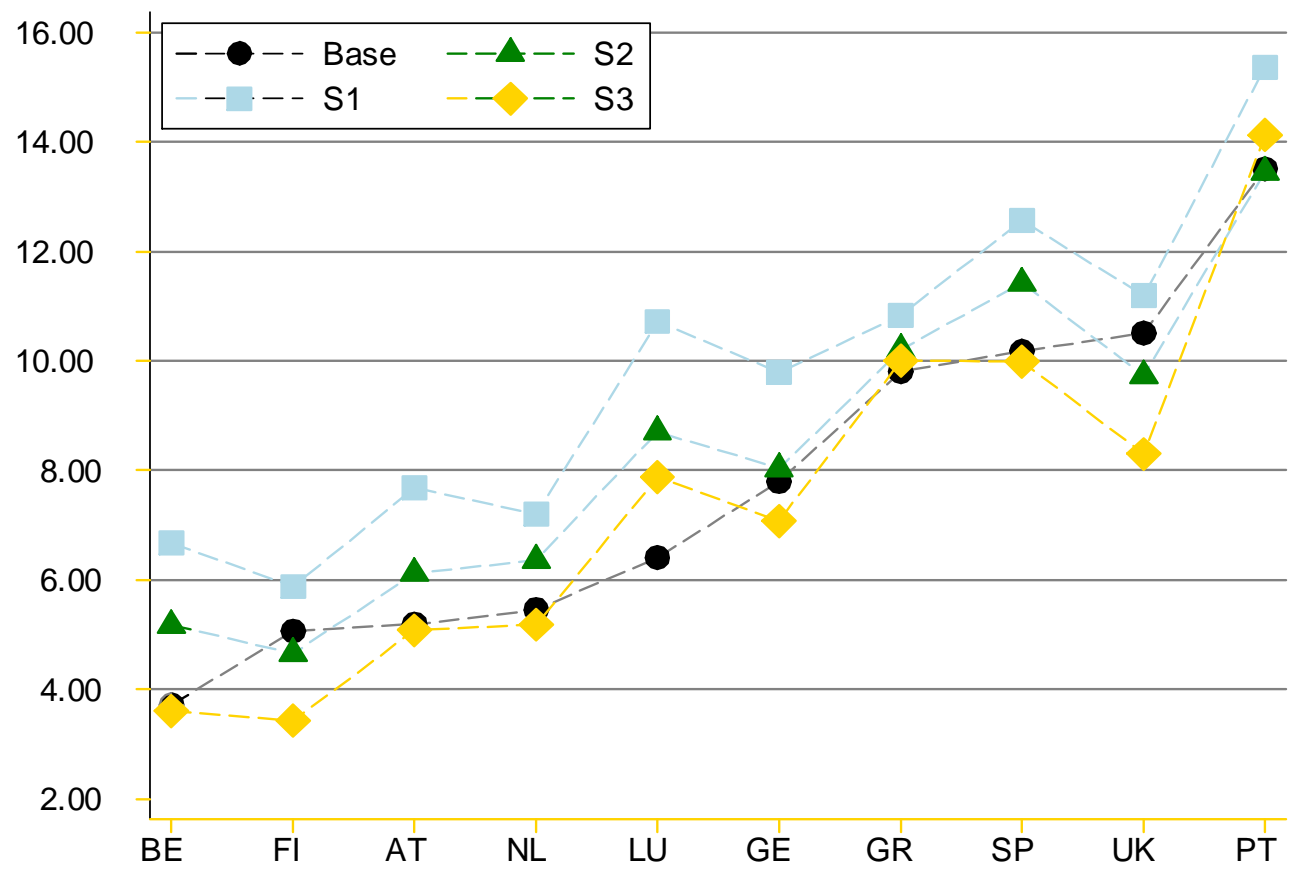

Figure 5: Richness rates by the headcount ratio (with constant richness line), \%

(2004). ${ }^{25}$ The results are presented in Figure 6. The polarisation of the income distribution is high in Southern countries and the UK and low in Continental Europe and Finland. A high income polarisation describes the phenomenon of a declining middle class resulting in an increasing gap between rich and poor. Therefore, the middle class is of less importance in the Southern countries and the UK. And indeed, in these countries, which have high baseline values of inequality, inequality decreases in scenario S3 (and S2 in the UK). The polarisation increases in most countries and scenarios (except for Finland and the UK in S2 and S3) implying a further declining middle class (see Table 7 in Appendix B). This measure is therefore summarising the effects on poverty and richness.

\footnotetext{
${ }^{25}$ Schmidt (2004) creates a polarisation index which in analogy to the Gini index (Lorenz curve) is based on a polarisation curve for better comparability of the results and their interpretations. Generally speaking, polarisation is the occurrence of two antipodes. A rising income polarisation describes the phenomenon of a declining middle class resulting in an increasing gap between rich and poor. The proportion of middle income households is declining while the shares of the poor and the rich are both rising.
} 


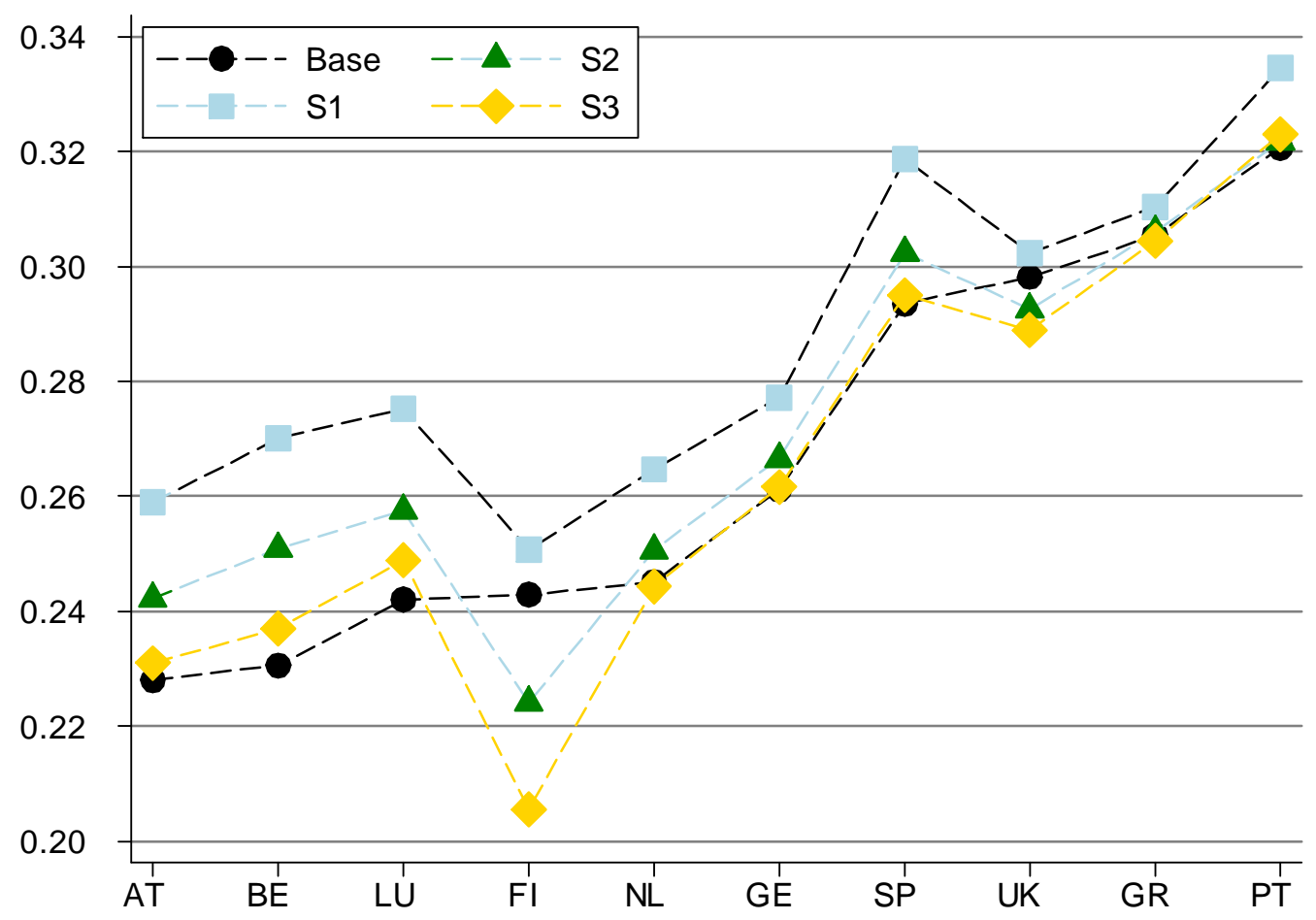

Figure 6: Polarisation by the Schmidt index

\subsection{Progressivity}

To analyse the impact of flat tax reforms on the redistributive effects of the tax system we compute several measures of tax progression. ${ }^{26}$ Figure 7 presents the values for the Suits index. In terms of progression the differences between the countries in the baseline scenario are rather small. Therefore it is not easy to distinguish homogeneous groups of countries in terms of tax progression. Progression is lowest in Spain and Luxembourg, whereas it is highest in Greece and the UK. Tax progression decreases under scenario S1 with a low tax rate in all countries in comparison to the baseline scenario, i.e. the incidence is more proportional. The values for scenario S2 depend on the country, whereas progressivity increases in S3 for all countries. Nevertheless the scenarios can be ranked in terms of all indices of progression in the following way: $I_{P R}(S 1)<I_{P R}(S 2)<I_{P R}(S 3)$.

The introduction of a revenue neutral tax reform always yields gainers and losers. Different

\footnotetext{
${ }^{26}$ We compute the measure of effective progression by Musgrave and Thin (1948), $P_{M T}=\frac{1-G_{Y}}{1-G_{X}}$, the indices of disproportionality by Kakwani (1977), $P_{K}=C_{T}-G_{X}$, Suits (1977), $P_{S}=1-\frac{L}{K}$, where $K$ denotes the area below the line of proportionality, and $L$ denotes the area below the Lorenz curve of tax payments against income, and Reynolds and Smolensky (1977), $P_{R S}=G_{X}-C_{Y}$, as well as the redistributive effect (of taxes) $P_{R E}=G_{X}-G_{Y}$ (with $Y$ disposable income, $X$ gross income, $T$ taxes, $G$ Gini coefficient and $C$ coefficient of concentration). See Table 10 in Appendix $\mathrm{C}$ for the detailed results.
} 


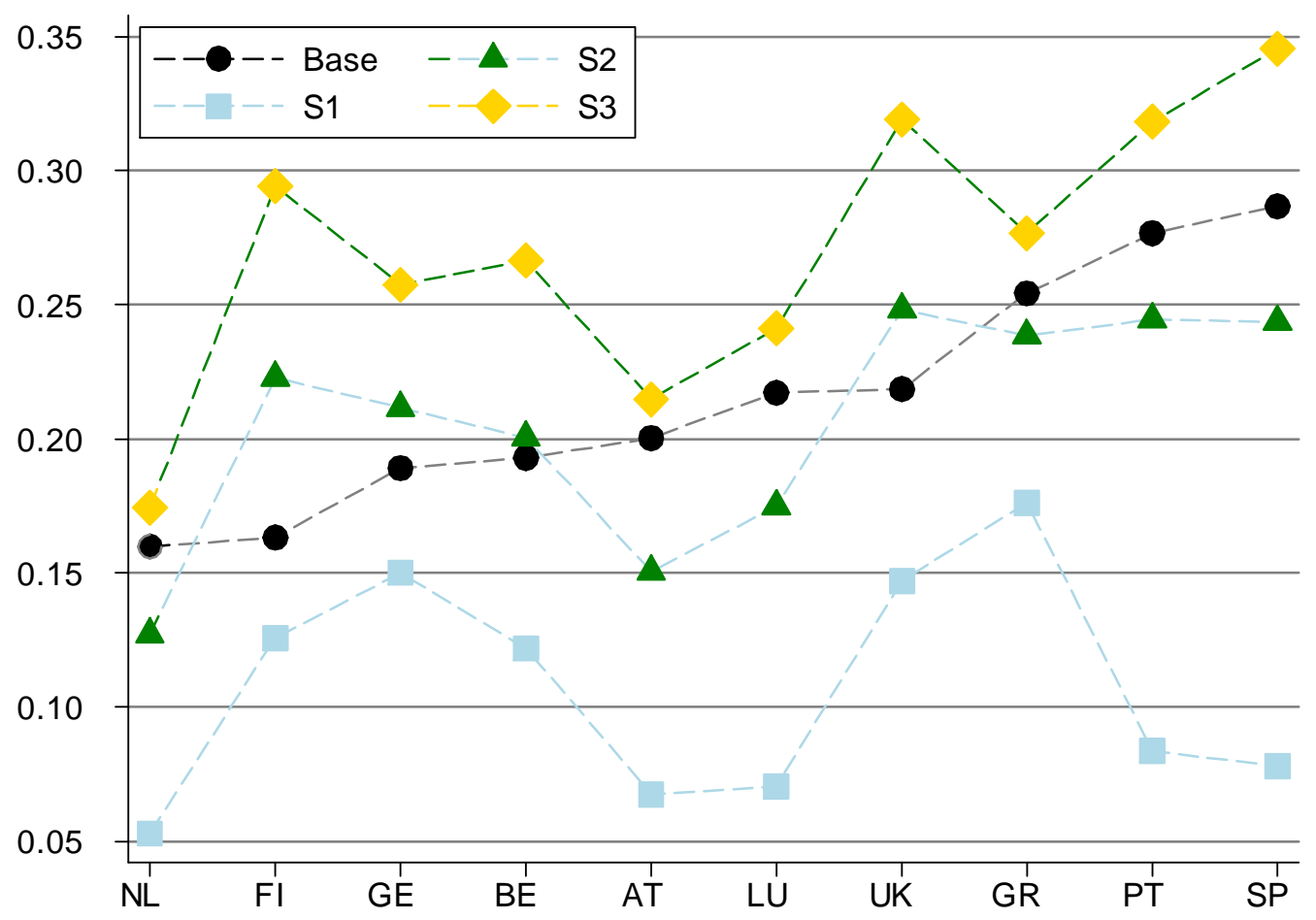

Figure 7: Tax progression by the Suits index

groups of taxpayers are affected differently by tax schedule flattening and tax base broadening. ${ }^{27}$ In the first scenario with the lowest tax rates the gains are solely concentrated in the top 1-2 deciles (only in Belgium also involving the 7th and 8th deciles). In the second scenario, some 9th decile households start losing instead of gaining; in the case of Finland and the UK the top decile loses as well while the bottom and middle deciles start gaining. In the third scenario only three countries are left with gains for the top decile (Luxembourg, the Netherlands and Spain). In addition to Finland and the UK, Greece, the Netherlands, Portugal and Spain also show gains for the lowest deciles. Germany under the third scenario is an exceptional case as only the middle income deciles gain.

The changes in mean disposable income are increasing (decreasing) with flat tax parameters (i.e. marginal tax rate and basic allowance) for low (high) income households. In other words, the lower (higher) the flat tax parameters the higher (lower) are the gains (losses) for high (low) income households. In most countries the relative losses in terms of disposable income remain high (or are even highest) for middle income households. These groups, however, usually play

\footnotetext{
${ }^{27}$ See Table 8 in Appendix $\mathrm{C}$ for the effect in terms of changes in mean disposable income by deciles. The range of changes is somewhat higher for the first (from $-9.7 \%$ to $+12.1 \%)$ and the third scenario $(-13.1 \%$ to $8.0 \%)$ compared with the second scenario (-5.5\% to $6.2 \%)$.
} 
an important role in the political process of a mature welfare state. Thus, these effects might explain why a flat tax is not very popular in Western Europe. ${ }^{28}$

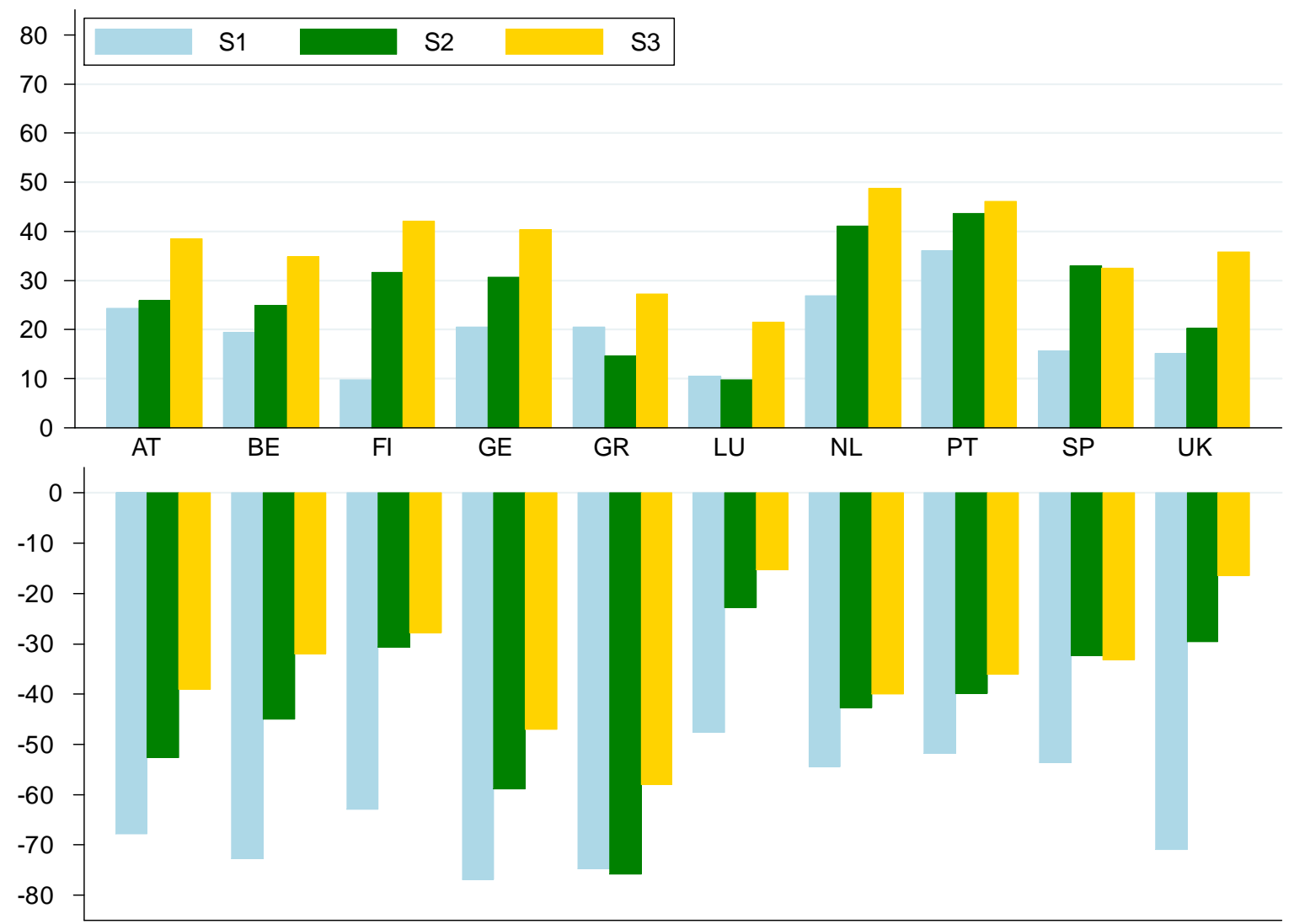

Figure 8: Share of winners and losers, \%

Figure 8 summarises gainers and losers ${ }^{29}$ by presenting the shares for each. There are more losers than winners in every country under the first scenario. Belgium, Finland and Germany show about the same share of winners and losers under the second scenario, while Greece, Portugal and the UK have most of the people with unchanged income. In the third scenario, only Austria and Luxembourg have still more losers; Germany, the Netherlands and Portugal have again roughly the same share of those gaining and losing and most people in Greece remain still in the 'no-change' category. The highest fraction of winners appears in Belgium and Finland for all scenarios and it is increasing over scenarios for most countries (except for Austria, Germany and Greece). If disposable income was chosen as the only criterion for an

\footnotetext{
${ }^{28}$ Fuest et al. (2008) for Germany and Jacobs et al. (2007) for the Netherlands find similar results for comparable scenarios.

${ }^{29}$ Households whose disposable income does not change more than 10 euros per month in either direction are regarded as „unchanged“. See also Table 11 in Appendix C.
} 
election decision, only the third flat tax scenario would have a majority in the population (in the sense of more winners than losers) for most countries.

\subsection{Work incentives: effective average and marginal tax rates}

In this section, we analyse the effects of flat tax reforms on the effective marginal (EMTR) and average (EATR) income tax rates faced by different groups of taxpayers as a measure for efficiency effects. The underlying idea is that average and marginal income tax rates affect labour supply and savings incentives. Therefore, changes in effective income tax rates may be considered as rough indicators for distortions caused by the tax system. ${ }^{30}$ Effective marginal tax rate shows at which rate an additional unit of income is taxed, whereas effective average tax rate shows the proportion of total taxes (including SICs) to market income. ${ }^{31}$ Changes in effective average tax rates are of special interest for the extensive labour supply margin which seems to be more important for particular subgroups at the bottom of the income distribution than the intensive margin which is affected by the effective marginal tax rate (see Heckman (1993) and Immervoll et al. (2007)).

Figures 9 and 10 present EMTRs and EATRs for the flat tax scenarios. ${ }^{32}$ Both measures already differ distinctively in the baseline scenario across countries. This can be attributed to several factors like, for example, the overall size of the government (and therefore the demand for public funds) and the general tax mix (i.e. the importance of the income tax) as well as economic differences between the countries. Mediterranean countries with the lowest EMTRs and EATRs have rather low income levels as well as the lowest relative levels of income taxation and social insurance contributions resulting in high inequality and polarisation of the income distribution. Finland and the UK which have average ETRs attribute much more importance to the income tax whereas social insurance contributions are relatively low. These social insurance contributions, however, play an important role in financing the Continental European welfare states where SIC are almost as high as income taxes ${ }^{33}$

\footnotetext{
${ }^{30}$ One should note, though, that average EMTRs and EATRs, in general, do not allow deriving conclusions for the expected labour supply reactions of individuals. These depend on the individual effective tax rates and their respective labour supply elasticities.

${ }^{31}$ We calculate EMTRs for the working age population (those aged 18-64) with positive employment or selfemployment income, increasing earnings of each individual in the household in turn by $3 \%$ while the change in all benefits and taxes (including social insurance contributions) is observed at the household level. We use the following formula: $E M T R_{i}=1-\frac{\Delta Y_{j}}{d_{i}}$, where $d_{i}$ is the income increment for individual $i$ and $Y_{j}$ disposable income of household $j$ to which this individual belongs. The effective average tax rate is also calculated for the working age population as: $E A T R_{i}=\frac{T_{i}}{X_{i}}$, where $T_{i}$ is total tax payments and $X_{i}$ the market income of individual $i$.

${ }^{32}$ See Tables 12, 13 and 14 in the appendix for the detailed results. The concentration (polarisation) of the EMTR distribution decreases (increases) with an increasing marginal tax rate, i.e. more people face low or high EMTRs whereas less individuals face medium EMTRs.

${ }^{33}$ See Table 4 in Appendix A for further information.
} 


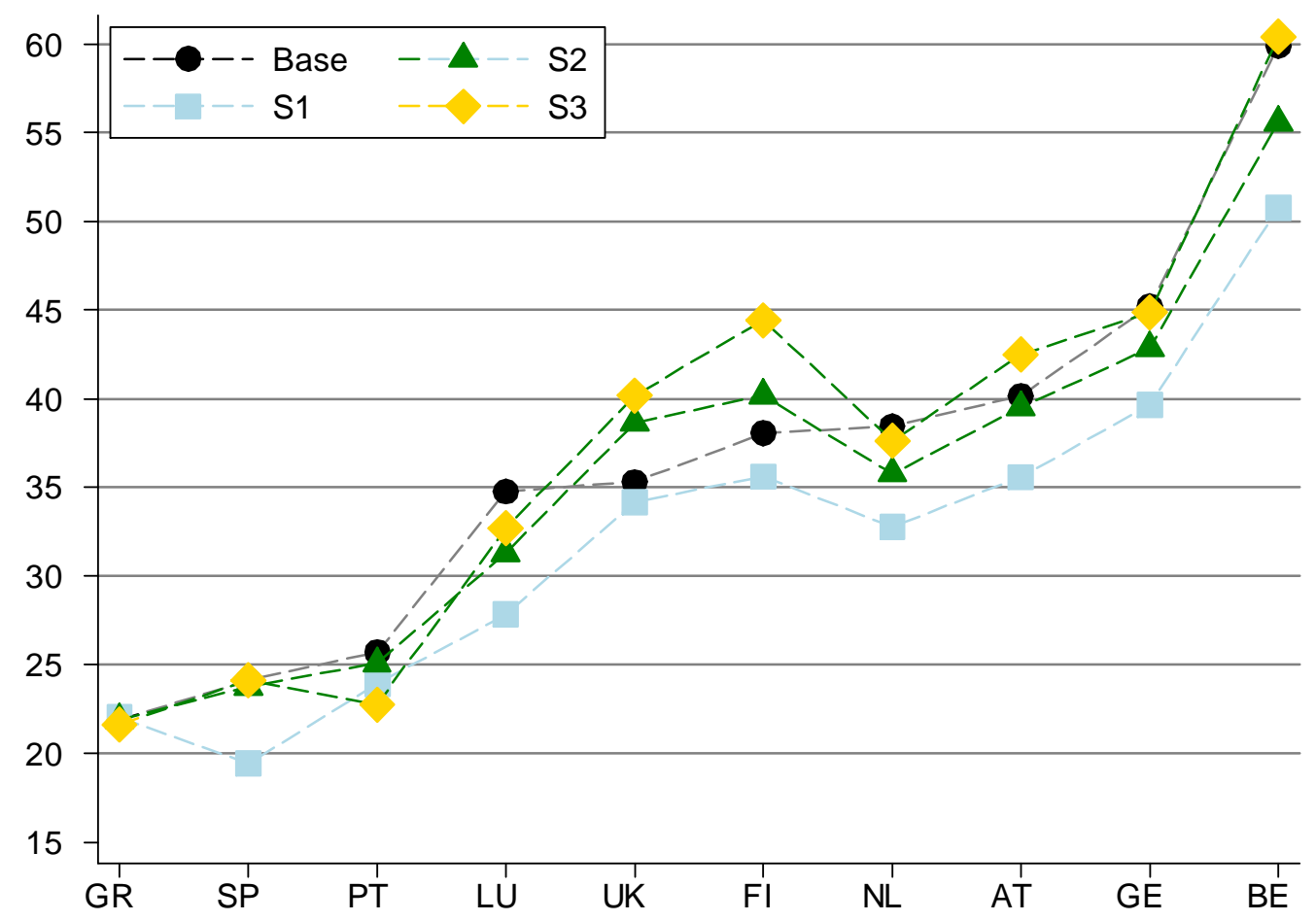

Figure 9: Effective marginal tax rates (mean), \%

The effective marginal tax burden is rather low in Mediterranean countries like Greece, Spain and Portugal; average in Luxembourg, UK, Finland and the Netherlands, and rather high in Austria, Germany and Belgium. The scenarios can be ranked in the following way (for most countries): $\operatorname{EMTR}(S 1)<\operatorname{EMTR}(S 2)<\operatorname{EMTR}(S 3)$. Therefore, effective marginal rates are increasing with statutory rates although revenue is kept constant. In scenario S1 the EMTRs decrease in all countries in comparison to the baseline, scenarios S2 and S3 depend on the country.

The effective average tax burden is rather low in Spain, Portugal, Greece, and Luxembourg; average in the UK, the Netherlands and Austria; and rather high in Finland, Belgium and Germany. The scenarios can be ranked as follows: $\operatorname{EATR}(S 1)>\operatorname{EATR}(S 2)>\operatorname{EATR}(S 3)$. Therefore, increasing the allowance dominates the increase in (statutory) marginal rate and leads to decreasing EATRs although the revenue is kept constant. In scenario S1 the EATRs increase in all countries (except BE) in comparison to the baseline, scenario S3 is always lower and S2 depends on the country.

To sum up, flat tax rates required to attain revenue neutrality with existing personal allowances (the first scenario) decrease EMTRs in all countries leading to increasing labour supply 


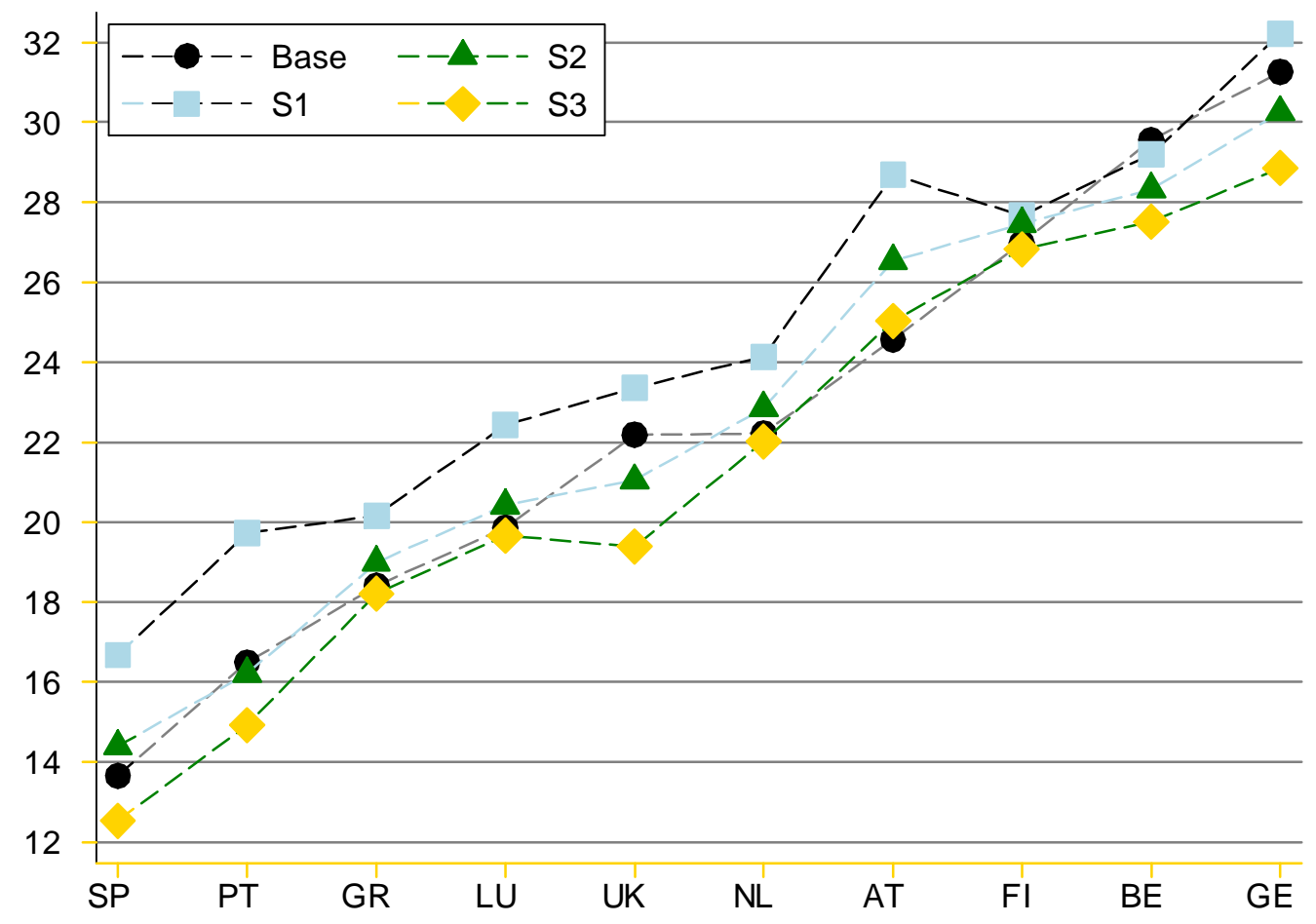

Figure 10: Effective average tax rates (mean), \%

incentives. ${ }^{34}$ On the other hand, (revenue neutral) flat rates necessary to keep the inequality levels close to their baseline values (the third scenario) lead to ambiguous effects. Incentives improve in Mediterranean and most Continental countries but worsen in other countries.

\subsection{Summary of results}

There are already distinct differences between the analysed countries under the present systems. In terms of distributional measures two groups of countries can be differentiated: inequality, (relative) poverty and richness and polarisation are rather high in Southern European countries (Greece, Portugal and Spain) and the UK, whereas they are rather low in Continental Europe (Austria, Belgium, Germany, Luxembourg) and Finland.

The variation in the effects of the scenarios across countries is summarised in Table 1. Different groups can be classified according to the welfare state typology of Esping-Andersen

\footnotetext{
${ }^{34}$ One should note, however, that higher incentives do not necessarily lead to higher labour supply and welfare but depend on the directions of the income and substitution effects based on the respective labour supply elasticities. However, recent studies for the Netherlands by Jacobs et al. (2007) and Germany by Fuest et al. (2008) are comparable with our scenarios S1 and S2. In summary, these studies find and increase in labour supply (and inequality) for scenario S1, whereas in scenario S2 inequality is held constant resulting in negligible efficiency effects.
} 
(1990). In the Nordic and Anglo-Saxon countries inequality, poverty and richness increase (and progression decreases) only in scenario S1. In the Southern European countries inequality increases in scenarios S1 and S2. In Continental Europe inequality increases in all three scenarios (except Germany). Incentives increase in all countries for scenarios S1 and S2 (except FI and UK) as well as for Mediterranean and Continental countries in scenario S3.

\begin{tabular}{|ll|lll|llll|lll|}
\hline & & \multicolumn{3}{|c|}{ Ineq./Pov./Rich. } & \multicolumn{3}{|c|}{ Polarisation } & \multicolumn{3}{|c|}{ LS incentives } \\
& & S1 & S2 & S3 & S1 & S2 & S3 & S1 & S2 & S3 \\
\hline \hline \multirow{5}{*}{ Continental } & AT & + & + & + & + & + & + & + & + & - \\
& BE & + & + & $(\sim)$ & + & + & + & + & + & - \\
& GE & + & + & $(\sim)$ & + & + & + & + & + & + \\
& LU & + & + & + & + & + & + & + & + & $(\sim)$ \\
& NL & + & + & $(+)$ & + & + & $\sim$ & + & + & $(+)$ \\
\hline Nordic & FI & + & - & - & + & - & - & + & - & - \\
\hline Anglo-Saxon & UK & + & $(-)$ & - & + & - & - & + & - & - \\
\hline \multirow{4}{*}{ Southern } & GR & + & + & - & + & $\sim$ & - & $(\sim)$ & $(\sim)$ & $(+)$ \\
& PT & + & + & - & + & $\sim$ & $\sim$ & + & + & + \\
& SP & + & + & $(\sim)$ & + & + & $\sim$ & + & + & $(\sim)$ \\
\hline
\end{tabular}

Table 1: Summary of simulation results

Note: the symbols have the following meanings: $+/-:$ significant increase (decrease) in all measures considered, $(+) /(-)$ : significant increase (decrease) in most measures, $\left({ }^{\sim}\right)$ : ambiguous results or no significant changes.

Our analysis shows that the selection of the schedule and tax base parameters is crucial for the effects of flat tax reforms in terms of equity and efficiency. Low parameter values that attain revenue neutrality with existing personal allowances decrease EMTRs and therefore increase labour supply incentives. This, however, leads to more inequality, poverty and polarisation as low rates benefit mainly those with high incomes at the expense of low and middle income households. On the other hand, higher flat rates keep the inequality levels unchanged. However, this does not necessarily imply strong disincentive effects for all countries. In fact, for some countries the EMTRs decrease in all three scenarios resulting in increasing incentives even in for scenario S3 with a high marginal rate.

\section{Conclusion}

Flat income taxes have become increasingly popular in Eastern Europe. However, this popularity has not yet reached Western European countries with well-established middle classes. Using EUROMOD we provide a microsimulation analysis of differt flat tax designs for selected Western European countries in a common framework. 
In general, a revenue neutral flat tax reform cannot overcome the fundamental equityefficiency trade-off. However, in some cases such as Greece, Portugal and Spain an increase in both equity and incentives is possible. These countries have the typical Mediterranean welfare state regime which can be seen as a rudimentary version of the Conservative (Continental) welfare system with a lack of a minimum income scheme. These welfare states provide a rather low level of social security (comparable to the Anglo-Saxon countries) based on low levels of taxes and redistribution. However, they also use contribution-based Bismarckian social insurance systems providing benefits depending on the level of previously earned income (like the Continental countries). Furthermore, emphasis is put on the role of the family as being a major part of the social care system. The income tax contributes only a minor part to the government budget (i.e. less than $10 \%$ of GDP), whereas indirect taxes are much more important and the social expenditures in general are lower (i.e. around 20\% of GDP) in comparison to other types of welfares states. ${ }^{35}$

As a consequence of its design, the Mediterranean welfare state regime is characterised by high inequality, poverty, richness and polarisation of the disposable income distribution. These distributional characteristics imply a lack of a well-established middle class. Therefore, the distributional effects of a flat tax reform that burdends the middle class are less adverse than in countries with a more equal income distribution. Switching to a flat tax regime in this setting can reduce inequality and increase efficiency in terms of labour supply incentives. However, the resulting marginal flat tax rates are still rather high.

When interpreting these results, one has to be aware of the fact that we limit our analysis to static models. However, flat taxes are also supposed to have positive dynamic efficiency and growth effects. ${ }^{36}$ These long-term effects might make increasing inequality acceptable. Nevertheless, the question arises whether a personal income tax reform is the best instrument to increase growth and employment. The user costs of labour and capital play an important role in determining the labour and investment demand. These user costs, however, are determined more by social security contributions and corporate taxes than by personal income tax.

Nevertheless, the immediate and short-term distributional effects analysed in this paper are most likely to be decisive for the political feasibility of a flat tax reform. The main problem of implementing a flat rate tax could be to convince a majority of the population that redistribution in favour of the highest income decile is acceptable. These distributional effects at the expense of the middle class help to explain why flat rate taxes have not been successful in the political process in Western Europe. However, our analysis shows that for some Mediterranean countries a flat tax can increase both equity and efficiency. This also suggests that these and

\footnotetext{
${ }^{35}$ See e.g. European Commission (2007), Eurostat (2006).

${ }^{36}$ Cf. Stokey and Rebelo (1995) or Cassou and Lansing (2004).
} 
other countries with similar income distributions and welfare state structures are more prone to follow such reforms.

\section{References}

Aaberge, R., Colombino, U. and Strøm, S. (2000), 'Labor Supply Responses and Welfare Effects from Replacing Current Tax Rules by a Flat Tax: Empirical Evidence from Italy, Norway and Sweden', Journal of Population Economics 13, 595-621.

Adam, S. and Browne, J. (2006), 'Options for a UK flat tax: some simple simulations', IFS Briefing Note No. 72.

Benedek, D. and Lelkes, O. (2007), 'Assessment of Income Distribution and a Hypothetical Flat Tax Reform in Hungary', Paper presented at the IMA 2007 conference, Euro Centre, Vienna.

Brook, A.-M. and Leibfritz, W. (2005), 'Slovakia's introduction of a flat tax as part of wider economic reforms', OECD Economics Department Working Paper No. 448.

Caminada, K. and Goudswaard, K. (2001), 'Does a Flat Rate Individual Income Tax Reduce Tax Progressivity? A Simulation for the Netherlands', Public Finance and Management $\mathbf{1}$ (4), 471-499.

Cassou, S. P. and Lansing, K. J. (2004), 'Growth Effects of Shifting from a Graduated-rate Tax System to a Flat Tax', Economic Inquiry 42(2), 194-213.

Chiu, W. H. (2007), 'Intersecting Lorenz curves, the degree of downside inequality aversion, and tax reforms', Social Choice and Welfare 28, 375-399.

Davies, J. B. and Hoy, M. (2002), 'Flat rate taxes and inequality measurement', Journal of Public Economics 84, 33-46.

Decoster, A. and Orsini, K. (2007), 'Verdient een vlaktaks zichzelf terug?', Leuvense Economische Standpunten, K.U. Leuven, Centrum voor Economische Studiën.

Esping-Andersen, G. (1990), The Three Worlds of Welfare Capitalism, Princeton University Press.

European Commission (2007), Taxation trends in the European Union, European Commission, Luxembourg. 
Eurostat (2006), Structures of the taxation systems in the European Union (Data 1995-2004), European Commission, Luxembourg.

Eurostat (2007), Taxation trends in the European Union: Data for the EU Member States and Norway, European Commission, Luxembourg.

Ferrera, M. (1996), 'The 'Southern Model' of Welfare in Social Europe', Journal of European Social Policy 6 (1), 17-37.

Foster, J., Greer, J. and Thorbecke, E. (1984), 'A class of decomposable poverty measures', Econometrica 52, 761-766.

Fuest, C., Peichl, A. and Schaefer, T. (2008), 'Is a flat tax reform feasible in a grown-up democracy of Western Europe? A simulation study for Germany', International Tax and Public Finance p. forthcoming.

Gaddy, C. G. and Gale, W. G. (2005), 'Demythologizing the Russian Flat Tax', Tax Notes International 43, 983-988.

González-Torrabadella, M. and Pijoan-Mas, J. (2006), 'Flat tax reforms: a general equilibrium evaluation for Spain', Investigaciones Económicas XXX (2), 317-351.

Gorodnichenko, Y., Martinez-Vazquez, J. and Peter, K. S. (2007), 'Myth and Reality of Flat Tax Reform: Micro Estimates of Tax Evasion Response and Welfare Effects in Russia', IZA Discussion Paper No. 3267.

Heckman, J. (1993), 'What has been learned about labor supply in the past twenty years?', American Economic Review Papers and Proceedings 85, 116-121.

Immervoll, H., Kleven, H., Kreiner, C. and Saez, E. (2007), 'Welfare Reform in European Countries: A Micro-Simulation Analysis', The Economic Journal 117 (516), 1-44.

Ivanova, A., Keen, M. and Klemm, A. (2005), 'Russia's 'flat tax', Economic Policy July, 397444.

Jacobs, B., de Mooij, R. A. and Folmer, K. (2007), 'Analyzing a flat income tax in the Netherlands', Tinbergen Institute Discussion Paper 2007-029/3.

Kahneman, D., Knetsch, J. L. and Thaler, R. H. (1991), 'Anomalies: The endowment effect, loss aversion, and status quo bias', Journal of Economic Perspectives 5, 193-206.

Kahneman, D. and Tversky, A. (1979), 'Prospect theory: An analysis of decision under risk', Econometrica 47, 263-291. 
Kakwani, N. C. (1977), 'Measurement of Tax Progressivity: An International Comparison', Economic Journal 87, 71-80.

Keen, M., Kim, Y. and Varsano, R. (2007), 'The 'flat tax(es)': Principles and experience', International Tax and Public Finance forthcoming.

Kuismanen, M. (2000), 'Labour supply and income tax changes: A simulation study for Finland', Bank of Finland Discussion Paper 5/2000.

Mitchell, D. (2007), 'Flat world, flat taxes', http://www.american.com, April 27.

Musgrave, R. A. and Thin, T. (1948), 'Progressive Taxation in an Inflationary Economy', Journal of Political Economy 56, 498-514.

Nicodeme, G. (2007), 'Flat tax: Does one rate fit all?', Intereconomics 42(3), 138-142.

OECD (2006), 'Fundamental reform of personal income tax', OECD Tax Policy Studies 13.

Peichl, A., Schaefer, T. and Scheicher, C. (2006), 'Measuring Richness and Poverty - A micro data application to Germany and the EU-15', CPE discussion paper No. 06-11, University of Cologne.

Reynolds, M. and Smolensky, E. (1977), Public Expenditures, Taxes, and the Distribution of Income: The United States, 1950, 1961, 1970, Academic Press, New York.

Schmidt, A. (2004), Statistische Messung der Einkommenspolarisation, Reihe: Quantitative Oekonomie, Band 141, Eul-Verlag, Lohmar.

Stokey, N. L. and Rebelo, S. (1995), 'Growth Effects of Flat-Rate Taxes', Journal of Political Economy 103(3), 519-550.

Suits, D. (1977), 'Measurement of Tax Progressivity', American Economic Review 67, 747-752.

Sutherland, H. (2001), 'EUROMOD: An Integrated European Benefit-Tax Model - Final Report', EUROMOD Working Paper EM9/01.

Sutherland, H. (2007), Euromod: the tax-benefit microsimulation model for the European Union, in A. Gupta and A. Harding, eds, 'Modelling Our Future: Population Ageing, Health and Aged Care', Vol. 16 of International Symposia in Economic Theory and Econometrics, Elsevier, pp. 483-488. 


\section{Appendices}

\section{A EUROMOD}

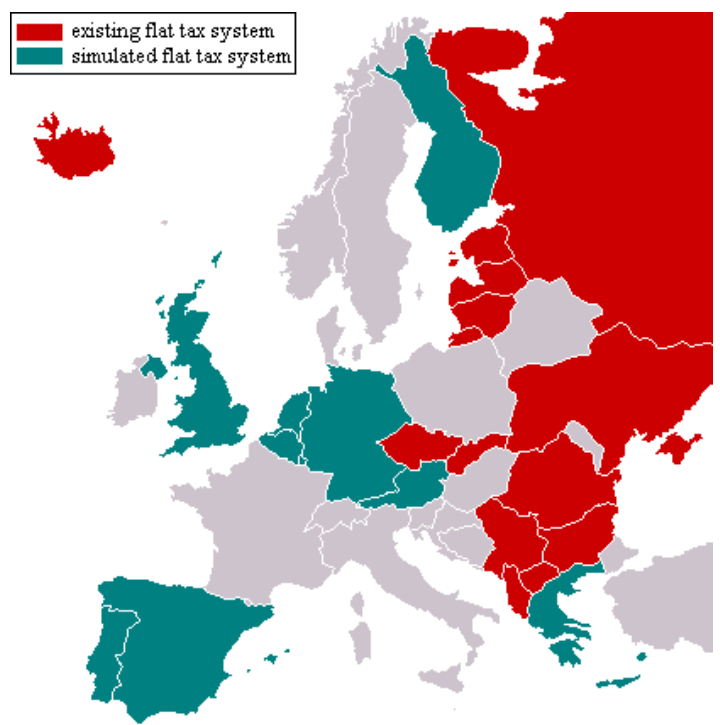

Figure 11: Existing (as of April 2008) and simulated flat tax systems in Europe

\begin{tabular}{|l|l|l|l|l|}
\hline & Input dataset for EUROMOD & $\begin{array}{l}\text { No of } \\
\text { households }\end{array}$ & $\begin{array}{l}\text { Date of col- } \\
\text { lection }\end{array}$ & $\begin{array}{l}\text { Reference time period } \\
\text { for incomes }\end{array}$ \\
\hline AT & Austrian version of EU-SILC & 4,521 & 2004 & annual 2003 \\
BE & Panel Survey on Belgian Households & 2,975 & 2002 & annual 2001 \\
FI & Income distribution survey & 10,736 & 2001 & annual 2001 \\
GE & German Socio-Economic Panel & 11,303 & 2002 & annual 2001 \\
GR & Household Budget Survey & 6,555 & $2004 / 5$ & annual 2003/4 \\
LU & PSELL-2 & 2,431 & 2001 & annual 2000 \\
NL & Sociaal-economisch panelonderzoek & 4,329 & 2000 & annual 1999 \\
PT & European Community Household Panel & 4,588 & 2001 & annual 2000 \\
SP & European Community Household Panel & 5,048 & 2000 & annual 1999 \\
UK & Family Expenditure Survey & 6,634 & $2000 / 1$ & month in 2000/1 \\
\hline
\end{tabular}

Table 2: EUROMOD input datasets (version C13) 


\begin{tabular}{|c|c|c|c|c|c|c|}
\hline & $\begin{array}{l}\text { No of } \\
\text { brackets }\end{array}$ & $\begin{array}{l}\text { Lowest } \\
\text { (pos) rate }\end{array}$ & Highest rate & $\begin{array}{l}\text { Form of the main tax } \\
\text { relief }\end{array}$ & Capital taxation & Tax unit \\
\hline $\mathrm{AT}$ & 4 & $21 \%$ & $50 \%$ & $\begin{array}{l}0 \% \text { tax bracket, tax } \\
\text { credit }\end{array}$ & flat tax $(25 \%)$ & individual \\
\hline $\mathrm{BE}$ & 5 & $25 \%$ & $50 \%$ & tax allowance & optional flat tax $(15 \%)$ & some sharing \\
\hline FI & 5 & $\begin{array}{l}\text { state } 12 \%, \\
\text { local } 15 \%\end{array}$ & $\begin{array}{l}\text { state } 35 \%, \\
\text { local } 19.75 \%\end{array}$ & $\begin{array}{l}0 \% \text { tax bracket (state), } \\
\text { tax allowance (local) }\end{array}$ & flat tax $(29 \%)$ & individual \\
\hline GE & 4 & $19.9 \%$ & $48.5 \%$ & $0 \%$ tax bracket & integrated & optional joint \\
\hline GR & 3 & $15 \%$ & $40 \%$ & $0 \%$ tax bracket & integrated & individual \\
\hline $\mathrm{LU}$ & 16 & $8 \%$ & $38 \%$ & $0 \%$ tax bracket & integrated & joint \\
\hline $\mathrm{NL}$ & 4 & $1.7 \%$ & $52 \%$ & tax credit & flat tax $(30 \%)$ & individual \\
\hline $\mathrm{PT}$ & 6 & $12 \%$ & $40 \%$ & tax credit & flat tax $(20 \%)$ & joint \\
\hline $\mathrm{SP}$ & 5 & $15 \%$ & $45 \%$ & tax allowance & integrated & optional joint \\
\hline UK & 3 & $10 \%$ & $40 \%$ & tax allowance & one bracket slightly reduced & individual \\
\hline
\end{tabular}

Table 3: Income tax systems, 2003

\begin{tabular}{|l|r|r|r|r|}
\hline & Original Income & Taxes & SIC & Benefits \\
\hline AT & 98.74 & 19.99 & 16.75 & 38.01 \\
BE & 108.20 & 28.31 & 13.06 & 38.27 \\
FI & 103.69 & 30.62 & 5.27 & 32.14 \\
GE & 108.06 & 21.16 & 17.24 & 30.30 \\
GR & 93.94 & 9.79 & 13.78 & 29.63 \\
LU & 94.45 & 13.65 & 11.86 & 31.05 \\
NL & 114.30 & 13.57 & 21.53 & 20.84 \\
PT & 100.40 & 12.08 & 10.02 & 21.70 \\
SP & 97.42 & 16.07 & 5.78 & 24.48 \\
UK & 107.15 & 22.79 & 5.82 & 21.46 \\
\hline
\end{tabular}

Table 4: Mean value of income components in relation to DPI, 2003 in \% 


\section{B Inequality, poverty and richness}

\begin{tabular}{|l|r|r|r|r|r|r|r|r|r|r|r|c|c|}
\hline & \multicolumn{1}{|c|}{ PL } & \multicolumn{3}{|c|}{ FGT0 (HCR) } & \multicolumn{4}{|c|}{ FGT1 } & \multicolumn{4}{|c|}{ FGT2 } \\
\hline & & Base & S1 & S2 & S3 & Base & S1 & S2 & S3 & Base & S1 & S2 & S3 \\
\hline AT & 859.22 & 11.06 & 16.19 & 13.70 & 12.61 & 1.93 & 2.97 & 2.45 & 2.25 & 0.58 & 0.87 & 0.73 & 0.69 \\
BE & 809.52 & 10.00 & 14.68 & 11.97 & 10.94 & 3.39 & 4.10 & 3.74 & 3.63 & 1.99 & 2.25 & 2.16 & 2.14 \\
FI & 838.33 & 12.24 & 12.76 & 9.95 & 9.64 & 2.17 & 2.17 & 1.75 & 1.74 & 0.63 & 0.60 & 0.52 & 0.52 \\
GE & 801.56 & 13.04 & 15.06 & 13.88 & 13.38 & 2.74 & 3.00 & 2.84 & 2.81 & 0.97 & 1.02 & 1.00 & 1.00 \\
GR & 437.40 & 19.48 & 20.54 & 19.51 & 19.50 & 6.36 & 6.50 & 6.37 & 6.36 & 3.34 & 3.37 & 3.34 & 3.34 \\
LU & $1,274.24$ & 9.31 & 14.64 & 11.83 & 10.72 & 1.10 & 2.09 & 1.46 & 1.30 & 0.25 & 0.46 & 0.31 & 0.28 \\
NL & 871.00 & 11.87 & 14.87 & 12.93 & 11.41 & 2.37 & 2.82 & 2.42 & 2.28 & 1.20 & 1.30 & 1.19 & 1.16 \\
PT & 347.43 & 20.89 & 23.65 & 21.22 & 21.44 & 4.75 & 5.59 & 4.78 & 4.71 & 1.40 & 1.71 & 1.40 & 1.38 \\
SP & 548.13 & 19.18 & 22.89 & 20.26 & 19.21 & 5.40 & 6.78 & 5.75 & 5.41 & 2.47 & 3.03 & 2.58 & 2.47 \\
UK & 575.07 & 16.17 & 17.16 & 15.38 & 15.08 & 3.00 & 3.13 & 2.90 & 2.88 & 1.05 & 1.08 & 1.03 & 1.03 \\
\hline
\end{tabular}

Table 5: Poverty line and rate

Sources: own calculation using EUROMOD version C13.

Note: PL: poverty line, FGT $\alpha$ : Foster et al. (1984) poverty measure.

\begin{tabular}{|c|c|r|r|r|r|r|r|c|c|c|c|c|c|}
\hline & RL & \multicolumn{5}{|c|}{ R0 (HCR) } & \multicolumn{5}{|c|}{ R1 } & \multicolumn{4}{|c|}{ R2 } \\
\hline & & Base & \multicolumn{1}{|c|}{ S1 } & \multicolumn{1}{|c|}{ S2 } & S3 & Base & S1 & S2 & S3 & Base & S1 & S2 & S3 \\
\hline AT & $2,864.06$ & 5.19 & 7.68 & 6.12 & 5.08 & 1.02 & 1.83 & 1.40 & 1.03 & 0.35 & 0.70 & 0.51 & 0.36 \\
BE & $2,698.39$ & 3.72 & 6,67 & 5.17 & 3.61 & 0.78 & 1.37 & 0.97 & 0.72 & 0.32 & 0.51 & 0.37 & 0.28 \\
FI & $2,794.42$ & 5.06 & 5.88 & 4.65 & 3.43 & 1.23 & 1.52 & 1.12 & 0.79 & 0.53 & 0.65 & 0.47 & 0.33 \\
GE & $2,671.85$ & 7.79 & 9.79 & 8.03 & 7.07 & 1.48 & 2.16 & 1.66 & 1.29 & 0.46 & 0.76 & 0.55 & 0.39 \\
GR & $1,458.00$ & 9.81 & 10.82 & 10.21 & 10.00 & 2.24 & 2.77 & 2.46 & 2.23 & 0.82 & 1.13 & 0.95 & 0.80 \\
LU & $4,247.46$ & 6.41 & 10.72 & 8.71 & 7.88 & 1.22 & 2.37 & 1.86 & 1.51 & 0.38 & 0.86 & 0.63 & 0.47 \\
NL & $2,905.09$ & 5.46 & 7.20 & 6.36 & 5.18 & 0.96 & 1.63 & 1.28 & 1.01 & 0.29 & 0.59 & 0.44 & 0.34 \\
PT & $1,158.09$ & 13.51 & 15.36 & 13.44 & 14.12 & 4.16 & 5.31 & 4.34 & 4.00 & 1.83 & 2.59 & 1.98 & 1.69 \\
SP & $1,827.09$ & 10.18 & 12.57 & 11.42 & 9.99 & 2.12 & 3.26 & 2.60 & 2.11 & 0.70 & 1.25 & 0.93 & 0.71 \\
UK & $1,921.48$ & 10.51 & 11.19 & 9.73 & 8.30 & 2.40 & 2.86 & 2.23 & 1.76 & 0.87 & 1.12 & 0.83 & 0.61 \\
\hline
\end{tabular}

Table 6: Richness line and rate

Sources: own calculation using EUROMOD version C13.

Note: RL: richness line, R $\alpha$ : Peichl et al. (2006) richness measure. 


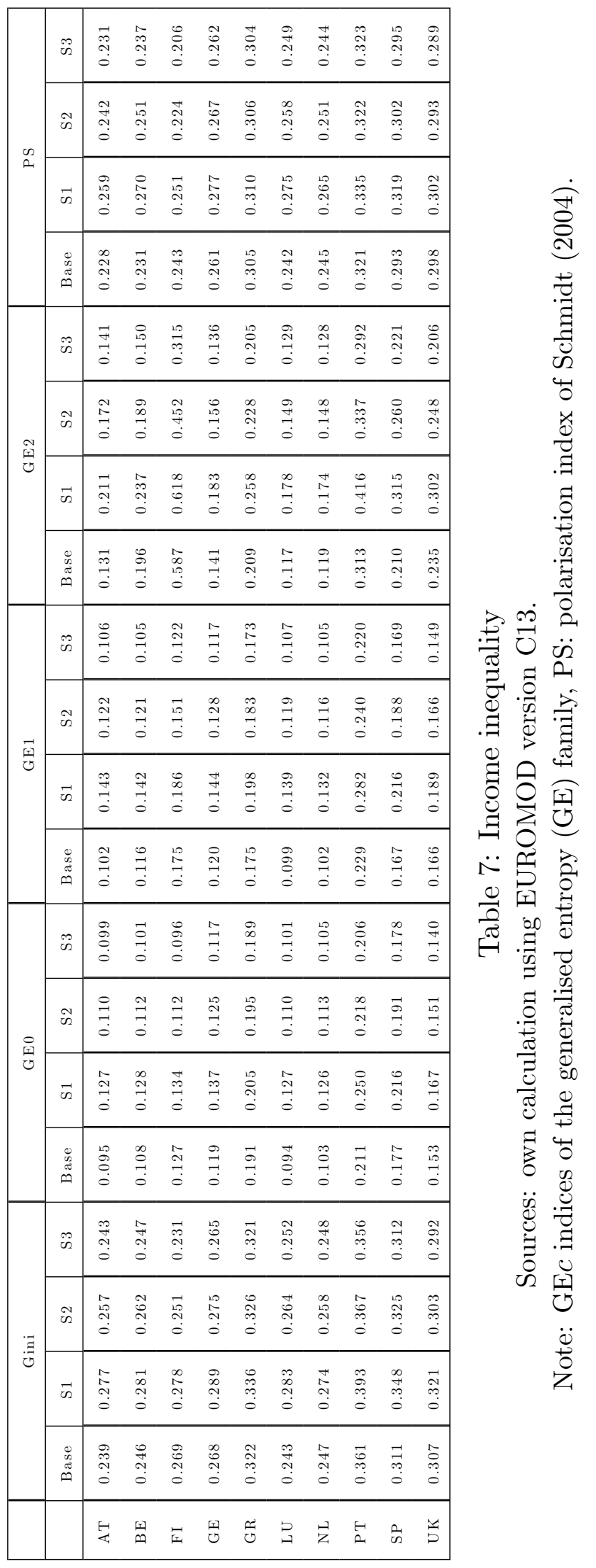




\section{Distribution of tax payments and disposable income}

\begin{tabular}{|c|c|c|c|c|c|c|c|c|c|c|c|c|c|c|c|}
\hline & \multicolumn{3}{|c|}{$\mathrm{AT}$} & \multicolumn{3}{|c|}{$\mathrm{BE}$} & \multicolumn{3}{|c|}{ F I } & \multicolumn{3}{|c|}{$\mathrm{GE}$} & \multicolumn{3}{|c|}{ GR } \\
\hline & S1 & $\mathrm{S} 2$ & S3 & S1 & $\mathrm{S} 2$ & S3 & S1 & $\mathrm{S} 2$ & S3 & S1 & S2 & S3 & $\mathrm{S} 1$ & $\mathrm{~S} 2$ & S3 \\
\hline 1 & -8.01 & -4.44 & -2.79 & -7.05 & -3.68 & -2.46 & 0.70 & 5.27 & 5.83 & -1.18 & -0.54 & -0.51 & -0.13 & 0.01 & 0.01 \\
\hline 2 & -9.70 & -5.51 & -2.73 & -8.19 & -4.09 & -1.34 & -1.47 & 4.80 & 7.98 & -3.62 & -1.19 & -0.05 & -1.29 & -0.04 & 0.08 \\
\hline 3 & -8.22 & -4.76 & -1.73 & -9.01 & -5.07 & -1.15 & -1.51 & 3.96 & 7.72 & -5.14 & -1.40 & 0.97 & -1.90 & -0.40 & 0.22 \\
\hline 4 & -7.51 & -4.44 & -1.68 & -6.48 & -2.98 & 0.21 & -1.72 & 2.54 & 6.17 & -4.76 & -1.46 & 1.05 & -2.66 & -0.66 & 0.47 \\
\hline 5 & -6.04 & -3.53 & -1.24 & -4.38 & -1.19 & 1.59 & -1.90 & 0.51 & 3.07 & -4.32 & -1.84 & 0.53 & -2.65 & -0.95 & 0.22 \\
\hline 6 & -4.73 & -3.04 & -0.99 & -1.59 & -0.30 & 1.22 & -1.90 & -0.71 & 1.01 & -3.49 & -1.12 & 1.20 & -2.89 & -1.43 & -0.26 \\
\hline 7 & -3.42 & -2.57 & -1.47 & 0.27 & 0.79 & 1.75 & -1.35 & -1.36 & -0.67 & -2.64 & -1.27 & 0.31 & -2.90 & -1.39 & -0.21 \\
\hline 8 & -1.70 & -1.85 & -1.27 & 2.26 & 1.31 & 0.81 & -1.13 & -2.26 & -2.56 & -1.59 & -1.14 & -0.34 & -2.01 & -0.96 & 0.11 \\
\hline 9 & 1.21 & -0.45 & -1.19 & 4.24 & 2.28 & 1.00 & 0.07 & -2.58 & -4.41 & 0.70 & -0.88 & -1.88 & -1.71 & -0.94 & 0.38 \\
\hline \multirow[t]{3}{*}{10} & 11.57 & 5.16 & -0.52 & 9.26 & 2.63 & -3.49 & 3.62 & -5.01 & -13.13 & 7.38 & 2.02 & -2.68 & 6.88 & 2.51 & -0.89 \\
\hline & \multicolumn{3}{|c|}{$\mathrm{LU}$} & \multicolumn{3}{|c|}{$\mathrm{NL}$} & \multicolumn{3}{|c|}{$\mathrm{PT}$} & \multicolumn{3}{|c|}{ SP } & \multicolumn{3}{|c|}{ U K } \\
\hline & $\mathrm{S} 1$ & S2 & S3 & $\mathrm{S} 1$ & $\mathrm{~S} 2$ & S3 & $\mathrm{S} 1$ & $\mathrm{~S} 2$ & S 3 & S1 & S2 & S3 & $\mathrm{S} 1$ & S2 & S3 \\
\hline 1 & -8.08 & -2.64 & -1.13 & -3.41 & 0.14 & 1.29 & -3.66 & 0.10 & 0.21 & -7.59 & -0.82 & 0.26 & -0.58 & 0.54 & 0.66 \\
\hline 2 & -9.15 & -4.36 & -2.11 & -4.34 & -1.05 & 0.70 & -5.38 & -0.34 & 0.42 & -9.22 & -2.89 & 0.05 & -1.32 & 1.44 & 2.54 \\
\hline 3 & -8.16 & -3.99 & -1.54 & -5.09 & -1.66 & 0.11 & -6.42 & -1.69 & -0.30 & -8.08 & -3.05 & 0.15 & -1.99 & 1.43 & 3.23 \\
\hline 4 & -8.75 & -5.23 & -2.94 & -4.60 & -2.16 & -0.43 & -6.45 & -0.35 & 0.89 & -7.51 & -3.43 & -0.84 & -2.24 & 1.80 & 4.27 \\
\hline 5 & -7.92 & -5.30 & -3.51 & -3.86 & -2.08 & -0.53 & -6.08 & -0.69 & 1.30 & -5.76 & -2.36 & 0.41 & -2.45 & 1.15 & 4.21 \\
\hline 6 & -6.10 & -4.61 & -2.79 & -2.50 & -1.59 & -0.41 & -6.57 & -0.88 & 1.78 & -5.30 & -2.53 & -0.12 & -2.40 & 0.50 & 3.17 \\
\hline 7 & -4.58 & -4.42 & -3.73 & -2.53 & -2.08 & -1.10 & -5.82 & -1.02 & 1.77 & -2.65 & -1.34 & 0.28 & -2.15 & -0.07 & 2.45 \\
\hline 8 & -2.65 & -2.97 & -2.51 & -0.88 & -1.21 & -1.03 & -4.07 & -1.60 & 1.84 & -0.81 & -1.20 & -0.69 & -1.42 & -0.85 & 0.31 \\
\hline 9 & 2.63 & 0.45 & -0.46 & 1.37 & -0.10 & -0.73 & 0.06 & -1.08 & 0.95 & 1.76 & -0.16 & -0.67 & -0.48 & -1.60 & -1.61 \\
\hline 10 & 12.05 & 6.16 & 1.51 & 9.75 & 4.91 & 0.95 & 11.24 & 2.59 & -2.99 & 11.79 & 5.19 & 0.05 & 6.23 & -0.26 & -5.77 \\
\hline
\end{tabular}

Table 8: Changes in disposable income by income decile, $\%$

Sources: own calculation using EUROMOD version C13. 


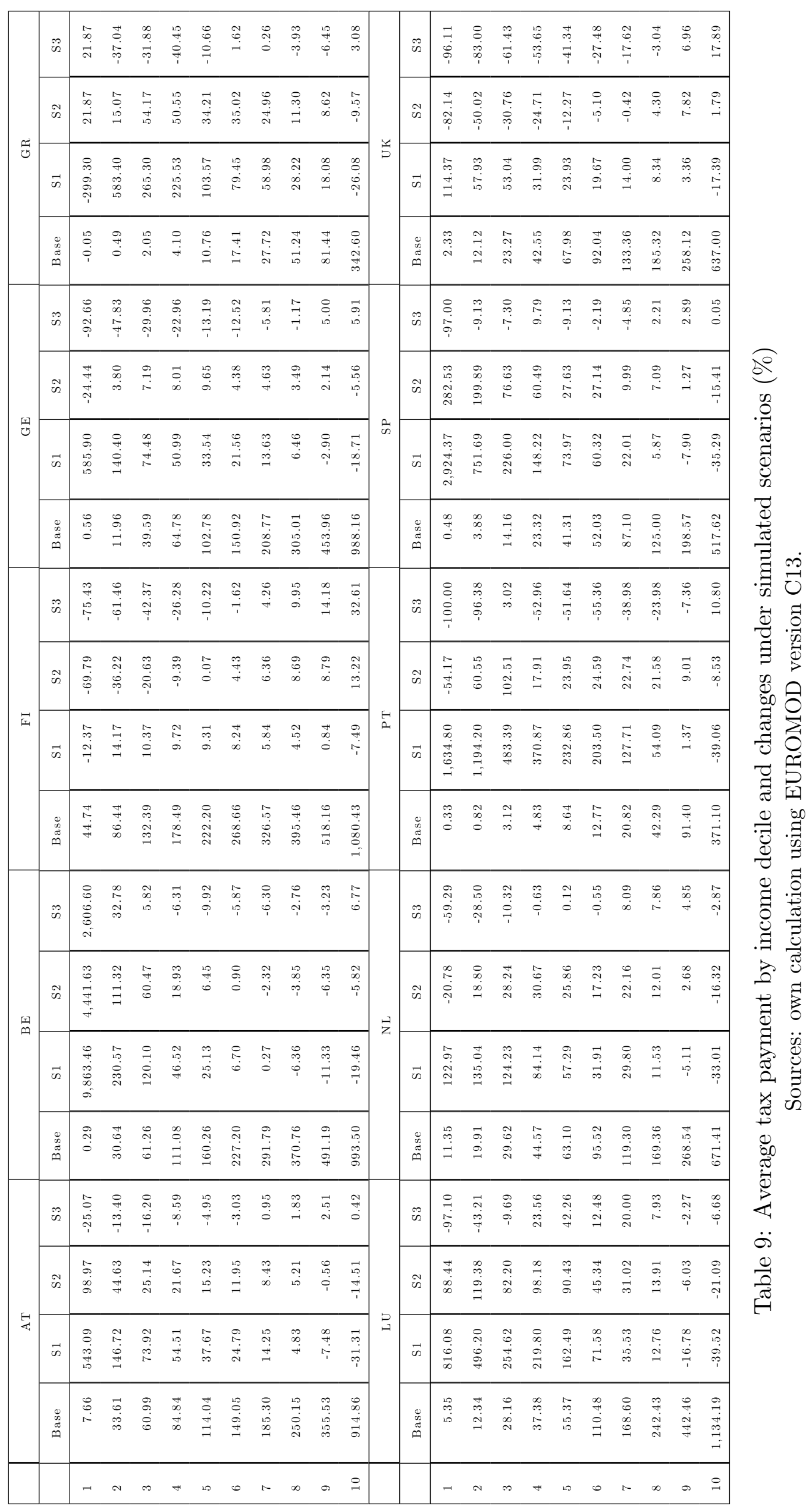




\section{Efficiency: effective average and marginal tax rate}

\begin{tabular}{|l|l|c|c|c|c|c|c|c|c|r|c|}
\hline & & AT & BE & FI & GE & GR & LU & NL & PT & SP & UK \\
\hline Base & median & 26.56 & 33.39 & 27.41 & 33.70 & 19.45 & 17.73 & 26.55 & 13.92 & 13.62 & 24.71 \\
& mean & 24.56 & 29.55 & 27.00 & 31.27 & 18.41 & 19.86 & 22.23 & 16.49 & 13.65 & 22.18 \\
S1 & median & 31.61 & 32.87 & 30.01 & 36.87 & 21.56 & 22.44 & 28.78 & 19.85 & 18.80 & 26.10 \\
& mean & 28.69 & 29.20 & 27.67 & 32.21 & 20.15 & 22.43 & 24.13 & 19.73 & 16.67 & 23.36 \\
S2 & median & 29.55 & 32.48 & 29.89 & 31.92 & 19.45 & 20.90 & 29.13 & 13.52 & 15.21 & 23.82 \\
& mean & 26.54 & 28.33 & 27.46 & 30.25 & 18.99 & 20.42 & 22.85 & 16.20 & 14.39 & 21.05 \\
& median & 26.02 & 31.37 & 28.81 & 26.56 & 19.45 & 17.74 & 26.76 & 11.00 & 8.60 & 19.23 \\
& mean & 25.03 & 27.52 & 26.83 & 28.85 & 18.21 & 19.66 & 22.02 & 14.92 & 12.53 & 19.39 \\
\hline
\end{tabular}

Table 12: Effective average tax rates at the individual level Sources: own calculation using EUROMOD version C13.

Note: EATR defined as (Income tax + SIC) / (market income). Includes individuals aged 18-64 with employment income but no self-employment and replacement incomes

\begin{tabular}{|l|l|c|c|c|c|c|c|c|c|c|c|}
\hline & & AT & BE & FI & GE & GR & LU & NL & PT & SP & UK \\
\hline Base & median & 41.04 & 51.02 & 43.40 & 50.01 & 19.45 & 35.46 & 45.36 & 23.00 & 28.83 & 31.40 \\
& mean & 40.16 & 59.90 & 38.07 & 45.20 & 21.87 & 34.76 & 38.45 & 25.72 & 24.11 & 35.30 \\
S1 & median & 35.37 & 40.54 & 39.62 & 45.98 & 21.40 & 26.85 & 33.26 & 21.32 & 22.88 & 31.90 \\
& mean & 35.59 & 50.76 & 35.60 & 39.66 & 22.02 & 27.84 & 32.76 & 23.92 & 19.43 & 34.17 \\
S2 & median & 43.62 & 49.23 & 49.16 & 49.87 & 19.45 & 35.94 & 32.27 & 21.60 & 27.65 & 41.90 \\
& mean & 39.52 & 55.57 & 40.19 & 42.85 & 21.89 & 31.29 & 35.78 & 25.08 & 23.76 & 38.65 \\
& median & 51.66 & 57.93 & 58.70 & 49.59 & 19.45 & 38.52 & 39.00 & 11.00 & 37.65 & 49.20 \\
& mean & 42.49 & 60.42 & 44.41 & 44.85 & 21.62 & 32.70 & 37.64 & 22.74 & 24.11 & 40.18 \\
\hline
\end{tabular}

Table 13: Effective marginal tax rates at the individual level Sources: own calculation using EUROMOD version C13.

Note: EMTR defined as [1 - (change in hh disposable income) / (increase in individual earnings)] and includes individuals aged 18-64 with positive earnings. 


\begin{tabular}{|c|c|c|c|c|c|c|c|c|c|c|c|}
\hline \multirow{13}{*}{ Base } & & $\mathrm{AT}$ & $\mathrm{BE}$ & FI & GE & GR & $\mathrm{LU}$ & NL & PT & SP & U K \\
\hline & $<0$ & 0.0 & 0.2 & 0.4 & 0.3 & 0.0 & 0.0 & 2.8 & 0.0 & 0.0 & 0.0 \\
\hline & {$[0-0.1)$} & 6.3 & 0.5 & 12.0 & 8.5 & 24.2 & 0.6 & 5.5 & 8.9 & 21.3 & 4.4 \\
\hline & {$[0.1-0.2)$} & 11.5 & 1.9 & 5.8 & 1.3 & 32.4 & 21.3 & 0.5 & 28.8 & 4.6 & 1.6 \\
\hline & {$[0.2-0.3)$} & 0.9 & 0.9 & 7.6 & 7.9 & 10.3 & 18.2 & 10.8 & 29.5 & 44.4 & 9.5 \\
\hline & {$[0.3-0.4)$} & 12.5 & 4.5 & 14.0 & 11.7 & 11.0 & 25.6 & 10.4 & 17.6 & 25.8 & 61.6 \\
\hline & {$[0.4-0.5)$} & 59.9 & 25.5 & 41.6 & 20.2 & 21.3 & 29.6 & 57.0 & 11.5 & 3.6 & 12.1 \\
\hline & {$[0.5-0.6)$} & 6.1 & 57.9 & 16.1 & 40.9 & 0.8 & 1.4 & 8.5 & 0.4 & 0.0 & 1.1 \\
\hline & {$[0.6-0.7)$} & 0.1 & 0.6 & 0.6 & 6.0 & 0.0 & 0.0 & 0.8 & 0.0 & 0.1 & 4.2 \\
\hline & {$[0.7-0.8)$} & 0.1 & 0.4 & 0.6 & 1.9 & 0.0 & 0.1 & 0.6 & 0.2 & 0.0 & 3.0 \\
\hline & {$[0.8-0.9)$} & 0.1 & 0.5 & 0.2 & 0.1 & 0.0 & 0.0 & 0.6 & 1.4 & 0.0 & 1.0 \\
\hline & {$[0.9-1)$} & 0.0 & 0.8 & 0.1 & 0.0 & 0.0 & 0.2 & 0.3 & 1.5 & 0.0 & 0.4 \\
\hline & $>1$ & 2.5 & 6.3 & 1.2 & 1.1 & 0.0 & 3.0 & 2.6 & 0.3 & 0.2 & 1.1 \\
\hline \multirow[t]{12}{*}{ S1 } & $<0$ & 0.0 & 0.1 & 0.0 & 0.3 & 0.0 & 0.0 & 2.7 & 0.0 & 0.0 & 0.0 \\
\hline & {$[0-0.1)$} & 4.0 & 1.0 & 14.6 & 12.0 & 19.9 & 0.5 & 4.8 & 3.5 & 7.9 & 4.4 \\
\hline & {$[0.1-0.2)$} & 0.4 & 2.4 & 0.7 & 0.7 & 16.4 & 16.7 & 15.4 & 16.0 & 37.8 & 0.1 \\
\hline & {$[0.2-0.3)$} & 10.7 & 0.1 & 0.9 & 21.7 & 25.3 & 76.2 & 23.3 & 57.3 & 53.9 & 18.8 \\
\hline & {$[0.3-0.4)$} & 78.3 & 28.8 & 76.8 & 6.1 & 37.7 & 3.3 & 16.7 & 19.4 & 0.0 & 65.0 \\
\hline & {$[0.4-0.5)$} & 3.3 & 57.6 & 3.2 & 47.0 & 0.7 & 0.0 & 7.7 & 0.1 & 0.0 & 1.0 \\
\hline & {$[0.5-0.6)$} & 0.1 & 0.5 & 0.5 & 6.8 & 0.0 & 0.1 & 24.3 & 0.2 & 0.0 & 0.3 \\
\hline & {$[0.6-0.7)$} & 0.0 & 0.6 & 0.9 & 1.3 & 0.0 & 0.1 & 0.8 & 0.0 & 0.0 & 4.3 \\
\hline & {$[0.7-0.8)$} & 0.1 & 0.5 & 0.8 & 2.8 & 0.0 & 0.1 & 0.7 & 0.1 & 0.1 & 3.5 \\
\hline & {$[0.8-0.9)$} & 0.1 & 0.3 & 0.4 & 0.1 & 0.0 & 0.1 & 0.4 & 1.3 & 0.0 & 1.1 \\
\hline & {$[0.9-1)$} & 0.2 & 1.4 & 0.1 & 0.0 & 0.0 & 0.6 & 0.5 & 0.9 & 0.0 & 0.5 \\
\hline & $>1$ & 2.9 & 6.8 & 1.2 & 1.2 & 0.0 & 2.4 & 2.6 & 1.1 & 0.2 & 1.1 \\
\hline \multirow[t]{12}{*}{ S2 } & $<0$ & 0.0 & 0.1 & 0.0 & 0.1 & 0.0 & 0.0 & 2.7 & 0.0 & 0.0 & 0.0 \\
\hline & {$[0-0.1)$} & 6.2 & 1.8 & 20.6 & 14.4 & 25.9 & 0.7 & 5.2 & 4.7 & 24.4 & 11.0 \\
\hline & {$[0.1-0.2)$} & 10.2 & 6.8 & 0.9 & 1.0 & 31.2 & 26.5 & 0.3 & 37.7 & 0.3 & 3.9 \\
\hline & {$[0.2-0.3)$} & 0.8 & 0.1 & 0.7 & 13.5 & 1.0 & 9.9 & 27.1 & 10.6 & 28.7 & 1.0 \\
\hline & {$[0.3-0.4)$} & 10.4 & 0.3 & 1.0 & 17.6 & 18.6 & 56.9 & 31.9 & 32.8 & 46.3 & 18.0 \\
\hline & {$[0.4-0.5)$} & 69.8 & 74.2 & 71.5 & 5.2 & 22.7 & 2.9 & 2.4 & 10.6 & 0.0 & 57.7 \\
\hline & {$[0.5-0.6)$} & 0.0 & 8.4 & 2.4 & 29.5 & 0.5 & 0.1 & 25.4 & 0.1 & 0.0 & 0.8 \\
\hline & {$[0.6-0.7)$} & 0.1 & 0.3 & 0.5 & 15.7 & 0.0 & 0.0 & 0.8 & 0.2 & 0.1 & 0.5 \\
\hline & {$[0.7-0.8)$} & 0.1 & 0.5 & 0.6 & 1.1 & 0.0 & 0.1 & 0.8 & 0.2 & 0.0 & 3.2 \\
\hline & {$[0.8-0.9)$} & 0.1 & 0.6 & 0.6 & 0.9 & 0.0 & 0.1 & 0.5 & 1.4 & 0.0 & 2.6 \\
\hline & {$[0.9-1)$} & 0.0 & 0.6 & 0.1 & 0.1 & 0.0 & 0.2 & 0.4 & 1.5 & 0.0 & 0.5 \\
\hline & $>1$ & 2.4 & 6.5 & 1.0 & 1.1 & 0.0 & 2.7 & 2.6 & 0.3 & 0.2 & 1.1 \\
\hline \multirow[t]{12}{*}{ S 3} & $<0$ & 0.0 & 0.1 & 0.0 & 0.1 & 0.0 & 0.0 & 2.7 & 0.0 & 0.0 & 0.0 \\
\hline & {$[0-0.1)$} & 6.4 & 1.9 & 25.1 & 15.4 & 28.6 & 0.7 & 5.5 & 8.0 & 43.1 & 20.3 \\
\hline & {$[0.1-0.2)$} & 20.2 & 11.4 & 1.1 & 2.2 & 38.9 & 40.9 & 0.2 & 58.1 & 0.5 & 6.7 \\
\hline & {$[0.2-0.3)$} & 1.6 & 0.3 & 0.7 & 20.4 & 1.7 & 1.5 & 12.5 & 0.4 & 0.4 & 1.1 \\
\hline & {$[0.3-0.4)$} & 0.3 & 0.3 & 1.1 & 1.3 & 0.4 & 9.5 & 37.0 & 23.7 & 23.9 & 1.2 \\
\hline & {$[0.4-0.5)$} & 11.3 & 0.4 & 1.2 & 16.9 & 16.3 & 42.2 & 22.3 & 0.6 & 31.9 & 21.1 \\
\hline & {$[0.5-0.6)$} & 57.7 & 72.0 & 66.9 & 2.4 & 14.2 & 2.1 & 3.8 & 0.0 & 0.0 & 43.8 \\
\hline & {$[0.6-0.7)$} & 0.0 & 6.0 & 1.9 & 28.7 & 0.0 & 0.0 & 12.0 & 5.9 & 0.1 & 1.0 \\
\hline & {$[0.7-0.8)$} & 0.0 & 0.5 & 0.4 & 10.8 & 0.0 & 0.1 & 0.7 & 0.2 & 0.0 & 0.1 \\
\hline & {$[0.8-0.9)$} & 0.0 & 0.8 & 0.4 & 0.2 & 0.0 & 0.0 & 0.4 & 1.4 & 0.0 & 2.6 \\
\hline & {$[0.9-1)$} & 0.1 & 0.5 & 0.3 & 0.5 & 0.0 & 0.2 & 0.3 & 1.4 & 0.0 & 1.1 \\
\hline & $>1$ & 2.4 & 5.9 & 0.8 & 1.1 & 0.0 & 2.8 & 2.5 & 0.3 & 0.2 & 1.1 \\
\hline
\end{tabular}

Table 14: Distribution of effective marginal tax rates by intervals (\%)

Sources: own calculation using EUROMOD version C13.

Note: EMTR defined as [1 - (change in hh disposable income) / (increase in individual earnings)] and includes individuals aged 18-64 with positive earnings. 